NBER WORKING PAPER SERIES

\title{
COLLEGE COST AND TIME TO COMPLETE A DEGREE: EVIDENCE FROM TUITION DISCONTINUITIES
}

\author{
Pietro Garibaldi \\ Francesco Giavazzi \\ Andrea Ichino \\ Enrico Rettore \\ Working Paper 12863 \\ http://www.nber.org/papers/w12863 \\ NATIONAL BUREAU OF ECONOMIC RESEARCH \\ 1050 Massachusetts Avenue \\ Cambridge, MA 02138 \\ January 2007
}

We would like to thank the administration of Bocconi University for providing the data and for answering our endless list of questions. We also thank Josh Angrist, Barbara Sianesi and seminar participants at Bocconi University, CREST conference on the "Econometric Evaluation of Public Policies" - Paris 2005, CEPR PPS 2006, CEPR EEEPE 2006, EALE 2006, ESSLE 2006, Hebrew University, Koc University, 'Max Planck Institute - Rostock, NBER Education Meeting 2006, Universitá di Roma Tor Vergata, Sebanci University for helpful comments and suggestions. Our special gratitude goes to Stefano Gagliarducci whose help was determinant in preparing the data and to Silvia Caló for further assistance. The views expressed herein are those of the author(s) and do not necessarily reflect the views of the National Bureau of Economic Research.

(c) 2007 by Pietro Garibaldi, Francesco Giavazzi, Andrea Ichino, and Enrico Rettore. All rights reserved. Short sections of text, not to exceed two paragraphs, may be quoted without explicit permission provided that full credit, including $(\mathrm{C}$ notice, is given to the source. 
College Cost and Time to Complete a Degree: Evidence from Tuition Discontinuities Pietro Garibaldi, Francesco Giavazzi, Andrea Ichino, and Enrico Rettore

NBER Working Paper No. 12863

January 2007, Revised April 2007

JEL No. C31,I2

\begin{tabular}{|c|c|}
\hline \multicolumn{2}{|c|}{ ABSTRACT } \\
\hline $\begin{array}{l}\text { Many students enrolled in academ } \\
\text { the normal completion time while } \\
\text { In particular, it does not increase w } \\
\text { time. Using a Regression Disconti } \\
\text { shows that an increase of } 1,000 \text { euro } \\
\text { by at least } 6.1 \text { percentage points wit } \\
\text { suggesting that an increase in cont } \\
\text { for instance in the presence of public }\end{array}$ & $\begin{array}{l}\text { ound the world take longer to obtain } \\
\text { is typically constant during the years } \\
\text { remains in a program beyond the norr } \\
\text { ata from Bocconi University in I } \\
\text { ation tuition reduces the probability of } \\
\text { penchmark average probability of } 80 \% \\
\text { is efficient when effort is suboptin } \\
\text { ducation, congestion externalities and }\end{array}$ \\
\hline $\begin{array}{l}\text { Pietro Garibaldi } \\
\text { University of Torino } \\
\text { Collegio Carlo Alberto } \\
\text { Via Real Collegio, } 30 \\
\text { 10024 Moncalieri, Torino - Italy } \\
\text { pietro.garibaldi@ unito.it }\end{array}$ & $\begin{array}{l}\text { Andrea Ichino } \\
\text { University of Bologna } \\
\text { Dipartimento di Economia } \\
\text { piazza Scaravilli, } 2 \\
\text { 40126, Bologna - Italy } \\
\text { andrea.ichino@unibo.it }\end{array}$ \\
\hline $\begin{array}{l}\text { Francesco Giavazzi } \\
\text { IGIER } \\
\text { Universita' L.Bocconi } \\
\text { 5, via Salasco } \\
\text { 20136 - Milano ITALY } \\
\text { and NBER } \\
\text { francesco.giavazzi@ unibocconi.it }\end{array}$ & $\begin{array}{l}\text { Enrico Rettore } \\
\text { University of Padova } \\
\text { Dipartimento di Scienze Statistiche } \\
\text { via Cesare Battisti } 241 \\
35121 \text {, Padova - Italy } \\
\text { enrico.rettore@ stat.unipd.it }\end{array}$ \\
\hline
\end{tabular}




\section{Introduction}

Many students enrolled in academic programs around the world take longer to obtain a degree than the normal completion time. Interestingly, this happens while college tuition typically does not increase (actually it often decreases) when a student remains in a program after its regular end. This paper shows that these two facts-the time profile of tuition and the speed of graduationare related and suggests that if tuition were raised after the regular end of a program the probability of late graduation would be reduced. It also suggests that this outcome would be efficient in the presence of public subsidies to education, congestion externalities and/or peer effects.

We discuss the link between the time profile of tuition and time to graduation in a simple model of human capital accumulation in which obtaining a degree is an uncertain outcome and requires time. Whereas the tuition a student pays during a program is a sunk cost, and thus has no effect on incentives, students anticipate the tuition they would pay if they remained enrolled beyond the regular completion time and react accordingly. As a result, a higher continuation tuition raises students' effort and increases the overall speed of completion. The core of the paper takes this simple prediction to the data.

We base our empirical analysis on detailed administrative data from Bocconi University in Milan. During the period for which we have information (1992-2000), Bocconi, a private institution, offered a 4-years college degree in economics. This dataset is informative on the question under study not only because more than $80 \%$ of Bocconi graduates typically complete their degree in more than 4 years, but also because it offers a unique quasi-experimental setting to analyze the effect of tuition on the probability of completing a degree within the normal time.

Upon enrollment in each academic year, Bocconi students in our sample are assigned to one of 12 tuition levels on the basis of their income, assessed by the university administration through the income tax declaration of the student's family and through further inquiries. A Regression Discontinuity 
Design (RDD) can then be used to compare students who, in terms of family income, are immediately above or below each discontinuity threshold. These two groups of students pay different tuitions to enroll, but should otherwise be identical in terms of observable and unobservable characteristics determining the outcome of interest, which in our case is the decision to complete the program in time. We focus on students in the last regular year of the program exploiting the fact that their current tuition is a good predictor of the tuition they would pay if they stayed in the program one more year. Thus, students on the two sides of a discontinuity threshold in the last regular year should expect to pay different tuitions in the following year if they do not graduate in time. Using this source of identification, we show that if the tuition paid by a student in the last regular year increases by 1,000 euro, the probability of late graduation decreases by at least 6.1 percentage points (with respect to an observed probability of $80 \%$ ). We also show that this decline in the probability of late graduation is not associated with an increase in the dropout rate or with a fall in the quality of students' performance as measured by the final graduation mark.

In light of these results, we proceed to ask whether there might be efficiency reasons suggesting that continuation tuition should be increased in real life academic institutions. We do not know much about the optimal length of the learning period for given amount of notions to be learned-this is in fact an issue that has been rarely explored in the literature. In principle a student could be left to decide the optimal speed at which she learns, and thus the time to graduation, and there is no reason why such a time should be the same for all students. In the absence of imperfections, private incentives would lead to completion times that are also socially optimal. We argue, however, that this is not the case at least in the presence of public subsidies to education, congestion externalities and peer effects. In the (frequent) situations in which these imperfections exist and generate externalities, tuition should be raised at the end of a program, relative to the marginal cost of providing education, since effort would otherwise be sub-optimally supplied.

The paper proceeds as follows. Section 2 describes the related literature. 
Section 3 presents the available international evidence on the time to degree completion and on the time profile of tuition. Section 4 proposes a simple model of human capital accumulation that delivers our main empirical prediction, namely, the existence of a negative causal effect of the size of continuation tuition on the probability of obtaining a degree beyond the normal completion time. Section 5 describes the data, while Section 6 shows how a Regression Discontinuity Design can be used to identify the causal effect of interest and discusses the robustness of our results with respect to some important complications generated by the institutional setting in which our evaluation takes place. Finally, Section 7 discusses when and why raising continuation tuition is efficient and Section 8 concludes.

\section{$2 \quad$ Related Literature}

There is a small literature looking at the effect of financial incentives on the time to complete a college degree, but its findings are ambiguous and typically not based on experimental evidence capable to control adequately for confounding factors and in particular for students' ability. Among the less recent non experimental studies, Bowen and Rudenstine (1992) and Ehrenberg and Mavros (1995) find evidence of an effect of financial incentives, in particular on completion rates and time to degree, while Booth and Satchell (1995) find no such evidence.

A more recent study by Hakkinen and Uusitalo (2003) evaluates a reform of the financial aid system in Finland aimed at reducing incentives to delay graduation, finding that the reform had some small effect in the desired direction. Similar in spirit, but with ambiguous findings, is the paper by Heineck et al. (2006) that evaluates the German reform of 1998 which introduced a fee on top of the normal tuition for students enrolled in a university program beyond the regular completion time. Both these studies, although based on the exogenous variation generated by a policy change, cannot fully control for confounding factors because they identify the effect of a tuition increase on delayed enrollment only on the basis of a comparison of students before 
and after the reform.

Similarly plagued by the likely presence of confounding factors is the study by Groen et al. (2006) which evaluates the effect of the Graduate Education Initiative (GEI) financed by the A.W. Mellon Foundation. This program distributed a total of 80 million dollars to 51 departments in 10 universities with the explicit goal of financing incentives aimed at reducing students' attrition and time to degree. By comparing these departments with a sample of similar control institutions, the study concludes that the GEI had a modest impact on the outcomes under study, mostly reducing student attrition rather than increasing degree completion. ${ }^{1}$

A larger and older literature studies the effect of tuition and financial aid on college enrollment. Van der Klaauw (2002) exploits the evidence generated by discontinuities in the rules for the concession of financial aid in a U.S. college. The methodology used in our paper is inspired by that study. In terms of substantive results, among the most recent and reliable contributions based on a quasi-experimental framework, Kane (2003) estimates that a $1,000 \$$ increase in college costs decreases enrollment rates by 4 percentage points while Dynarski (2003) finds that a grant aid of 1,000\$ increases the probability of attending college by 3.6 percentage points. Albeit related to our work, however, the question addressed by this literature is very different. ${ }^{2}$

Closer to our research goal are instead some recent papers that study, with mixed results, the effect of merit based financial incentives on indicators of student's performance. Angrist and Lavy (2002) run different trials offering financial incentives to Israeli highschool students aimed at increasing degree completion and conclude that significant gains can be obtained by offering cash awards in low-achieving schools. Dynarski (2005) finds substantial positive effects of merit aid programs in Georgia and Arkansas on the rate of

\footnotetext{
${ }^{1}$ Other papers study different non-financial incentives affecting graduation times: for example, demographic characteristics in Siegfried and Stock (2001); supervisor quality in Van Ours and Ridder (2003) and labor market conditions in Brunello and WinterEbmer (2003). Dearden et al. (2002) study instead the effects of financial incentives on educational choices of highschool graduates.

${ }^{2}$ See the surveys in Leslie and Brinkman (1987) and Dynarsky (2002).
} 
degree completion. On the contrary, within a randomized field experiment at a large Canadian university, Angrist, Lang and Oreopulos (2006) find weak effects of merit scholarship on grades and only for females. Similarly, Leuven et al. (2006) perform a field experiment in which first year university students can earn financial rewards for passing all first year requirements and find small and non-significant average effects on passing rates and collected credit points.

Among the papers finding positive effects, Kremer et al. (2005) is particularly relevant from our viewpoint. These authors conducted a randomized experiment in Kenia that offered school fees exemption and large cash awards to girls who scored well on academic exams. Interestingly, they find that financial incentives to student performance have positive externalities, since boys, who were ineligible for the award, also experienced an improvement in exam scores. The same happened for girls with low pretest scores who were very unlikely to win. The authors conclude that these large externalities address some of the equity concerns raised by critics of merit awards, and provide further rationale for public education subsidies. This is particularly relevant in our context because, as we argue in Section 7, the existence of peer effects is one of the reasons that justify an increase in continuation tuition, relative to the marginal cost of providing education, with the goal of inducing students to exert the socially optimal amount of effort.

To summarize, the mixed results of this literature may be a consequence of the more general ambiguity of the effects of monetary incentives highlighted by Gneezy and Rustichini (2000) and certainly require more research based on (quasi-)experimental evidence, which is our goal in this paper.

\section{Time to degree and time profile of tuition around the world}

A simple Google search of the words "Time to degree completion" produces an endless series of documents suggesting that throughout the world there is a generalized concern for the fact that a large fraction of students remains 
in educational programs beyond their normal completion times. Moreover, in many cases this tendency appears to have increased in recent years.

At the Ph.D. level in the U.S. these are well known facts that have generated widespread concern. In the representative sample collected by Hoffer and Welch (2006), the median time to obtain a Ph.D was 9 years in 1978 and increased to 10.1 years in 2003 with a similar pattern across fields. Such a number of years is almost twice what most universities consider as the regular completion time (i.e. $4-5$ years). These findings are confirmed also by OSEP (1990), Ehrenberg and Mavros (1995), Groen et al. (2006) and Siegfried and Stock (2001).

Perhaps less well known is the fact that a problem exists in the U.S. also at the undergraduate level where, according to Bound at al (2006), time to completion of a degree has increased markedly over the last two decades. These authors compare two cohorts of students who graduated from highschool in 1972 and in 1992 finding that the fraction receiving a degree within 4 years dropped from $57.6 \%$ to $44.0 \%$ and the average time to degree increased by more than one-quarter of a year. Beyond the fact that the increase in time to degree is localized among graduates of non-selective public colleges and universities, they conclude that changes in observable characteristics of the two cohorts do not contribute to explain the increase in time to degree.

A long series of documents, available on the internet, confirms this general finding. The U.S. Department of Education (2003), reports that firsttime recipients of bachelor's degrees in 1999-2000 took on average "about 55 months from first enrollment to degree completion". This is about one year more than the normal completion time of 45 months. The University of Southern California finds for its graduates of the academic years 96/97 00/01 that in all fields more than 12 quarters (the standard duration) are needed on average to obtain a degree. While in the social sciences the delay is more limited (12.2 quarters on average) in engineering and natural sciences completion time reaches 13.5 quarters. A report of the State of Illinois Board of Higher Education (1999) shows that only " $25 \%$ of the entering freshmen of 
the classes of 1987 through 1992 at the Illinois public universities graduated within 4 years", while $45 \%$ had not yet graduated at the end of the fifth year. Similarly at UCDavis (2004), out of 5153 bachelor's degrees conferred in 2002-03, $46 \%$ of the students obtained a degree in more than 4 years. Even at the level of 2-year community colleges there is evidence that delayed completion is an issue, as indicated by Gao (2002), who finds that only $45.2 \%$ of the first-time full-time freshmen at the Collin County Community College in Texas completed their studies within $150 \%$ of the legal duration.

The situation is similar in Canada where a 2003 report of the Association of Graduate Studies indicates that “... in many universities times to completion were longer than desired." Data are less easy to find for other countries, but the problem of the excessive time to degree completion is certainly not restricted to North America. A survey conducted by Brunello and Winter-Ebmer (2003) on 3000 Economics and Business college students in 10 European countries, finds that the percentage of students "expecting to complete their degree at least one year later than the required time ranges from $31.2 \%$ in Sweden and $30.8 \%$ in Italy to close to zero in the UK and Ireland. While Swiss and Portuguese students are close to the Anglo-Saxon pattern (3.5\% and $4.6 \%$ respectively), French and German students lie in between these extremes (17.1\% and 10\% respectively)." The web site of the Spanish Ministerio de Educacion y Ciencia reports that out of 91238 graduates of the three year undergraduate program, only 38581 completed their studies in time, and 33791 needed from 4 to 5 years. For the Netherlands, Van Ours and Ridder (2003) analyse the administrative data of three universities and find that "No Ph.D. student defends his or her thesis within three years, while a few students graduate in three to four years. Most students finish in five to seven years after the start, and after seven years the fraction remains almost constant, i.e. there are few graduations after seven years". According to Hakkinen and Uusitalo (2003) the problem of reducing time to graduation has been on the Finnish government agenda since at least 1969, given that Finland is second only to Italy, among OECD countries, in terms of average age of tertiary graduation. 
Indeed, the country where the problem is perhaps more serious is Italy, which offers the data used in the econometric analysis of this study. As shown in Table 1 Italy is the Oecd country with the smallest employment rate in the 25-29 age bracket, the highest enrollment rate in education in the 25-29 age bracket and the (second) lowest university graduation rate in the 35-44 age bracket. Since it is unlikely that cohort effects alone may explain these figures, it seems that while most Italian youths remain in educational institutions for a longer period than youths in other comparable countries, very few of them complete their studies and obtain a degree. This is not because these Italian youths drop out from a legal point of view, otherwise we would not see so many of them registered as "non-employed, in education". The fact is that Italian students have an abnormal tendency to extend their permanence in a university program beyond the normal completion time, as documented in Dornbusch at al. (2000).

Table 2 shows that while on average the mean legal duration of an Italian university program was 4.39 years, in a representative sample of 1995 graduates, the median effective duration was 7.00 years and the mean was 7.41. Moreover this tendency appears to be common to all fields. Table 3 shows that out of 1,684,993 students enrolled in Italian universities during the academic year 1999-00, 41.1\% are classified as Fuori Corso, i.e. they have been enrolled for more than the legal length of their university program. Of the 171,086 graduates of the same year, 83.5\% obtained their degree as Fuori Corso students.

Interestingly, while throughout the world obtaining a degree within the normal completion time is becoming the exception rather than the rule, university tuition is often structured in a way such that students pay the same for each year of enrollment, whether on schedule or beyond normal completion time. In some cases-one example is Italy-students pay less when they enroll as Fuori Corso. We are aware of only three cases that go in the opposite direction. In Germany a tuition ranging between 500 and 900 euro was introduced for Fuori Corso students in different landers between 1998 and 2005, in a time when regular students paid no fee (see Heineck et al, 2006). 
Similarly, the Finnish government passed in 1992 a reform aimed at reducing financial aid for students who delayed graduation (see Hakkinen and Uusitalo, 2003). In the same spirit, the Spanish system foresees that students pay for the credits they acquire by passing exams, but the cost of each credit increases with the number of times the student tries to pass the exam.

Outside of these three cases, there seems to be no evidence that academic institutions pay any attention to the possibility that the time profile of tuition and the speed of graduation might be related. In the rest of this paper we show, theoretically and empirically, that a link may instead exist with possibly important efficiency consequences.

\section{A simple theory}

We consider a risk neutral individual enrolled in school. The education investment takes time and has a random outcome: graduation is not guaranteed and it can take one or two periods to complete the degree, that is graduation-if it happens-can happen either in period 1 or in period 2. The normal completion time is period 1 while the second period is the extra-time required to graduate beyond regular completion. We assume that there is no discounting. In each period the probability of graduating depends linearly on individual effort at time $t$ and we indicate it simply with $e_{t}$. Market returns depend on whether students have graduated and on the speed at which they have completed their studies.

At time $t=1$ there is the first attempt to graduate. Successful graduation in the first period leads to a market return equal to $\beta w$, where $w$ is the outside option and $\beta>1$. Education involves both financial and psychological costs. The tuition at time $t=1$ is indicated with $\tau_{1}$ and it represents the marginal technological cost of providing education. Students in each period also face a (psychological) convex cost of education that we express as

$$
C_{t}(e)=\lambda+\frac{x e_{t}^{2}}{2}
$$

where $x$ is an ability parameter, $e$ is effort and $\lambda$ is a parameter that in- 
dividuals take as given. ${ }^{3}$ The marginal cost of acquiring education, $x e_{t}$, is increasing in effort. There is thus a link between ability and effort with better students facing a lower marginal cost of effort (a lower $x$ means higher ability). An obvious interpretation of $x$ is a measure of "learning stress". For given effort, students with higher $x$ find it more costly to acquire education.

A student may fail to graduate in period 1, the normal graduation time. If this happens, she faces a refinancing decision. Students who refinance education have a second attempt to graduate. The financial cost, that is tuition at time $t=2$, is indicated with $\tau_{2}$, where $\tau_{2}$ is the technological cost of providing education to a student who has refinanced her education. In other words, $\tau_{2}$ is the continuation tuition. Successful graduation in the second period leads to a return equal to $\beta \delta w$ with $0<\delta<1$ but such that $\beta \delta>1$. Students who fail to graduate in $t=2$ get the outside option $w$.

The equilibrium is described by the optimal effort levels (or graduation probabilities) $e_{1}$ and $e_{2}$ at time $t=1$ and $t=2$. The model is solved backward, beginning with the effort choice at time $t=2 .{ }^{4}$

Our main interest is the link between continuation tuition and speed of graduation. In this section we derive testable implications concerning the relationship between these two variables; a discussion of normative implications is postponed to Section $7 .^{5}$

Working backward, we first assume that an individual refinances education at time $t=2$. We compute optimal effort at time $t=2$, and indicate with $U_{2}\left(e_{2}, \tau_{2}\right)$ the lifetime utility of an individual that continues education

\footnotetext{
${ }^{3}$ This parameter plays a role in a possible extension of the model that we discuss in footnote 28.

${ }^{4} \mathrm{~A}$ model with sequential schooling choices, uncertainty and drop out is described by Altonji (1993). In that model there is no effort choice and the link between effort and speed of graduation is not analyzed. Most of the emphasis of that paper is on college choice, i.e. humanities versus math, and individuals have different attitudes toward different fields.

${ }^{5}$ Note that our discussion is for a fixed level of income and does not consider explicitly the individual's ability to pay. In this interpretation the time profile of tuition should be read as a pure technological parameter, as if it were associated to the marginal cost of providing education. Such restriction is nevertheless consistent with our empirical specification.
} 
at time $t=2$. The expression is

$$
U_{2}\left(e_{2}, \tau_{2}\right)=e_{2} \beta \delta w+\left(1-e_{2}\right) w-\left(\tau_{2}+\frac{x e_{2}^{2}}{2}+\lambda\right)
$$

With probability $e_{2}$ the individual becomes a late graduate and enjoys a market return equal to $\beta \delta w$ while with the complement probability she will accept the outside option $w$. The financial cost of education (the tuition) is $\tau_{2}$ plus the convex cost $C_{2}(e)$. Simple algebra shows that the optimal effort is

$$
e_{2}^{*}=\frac{w[\beta \delta-1]}{x}
$$

Two remarks are in order

Remark 1 The time profile of tuition does not affect optimal effort in the second period

Remark 2 The lower the student ability, the lower the effort in the second period

The first remark derives from the fact that $\frac{\partial e_{2}^{*}}{\partial \tau_{2}}=0$. Tuition is a sunk cost when the student chooses effort and it affects neither the psychological cost nor the marginal return, so that it can not have an impact on the marginal effort. The second remark (which derives from $\frac{\partial e_{2}^{*}}{\partial x}<0$ ) suggests a complementarity between ability and effort. Other things equal, the better the student the higher the effort.

Refinancing is optimal at time $t=2$ if and only if $U_{2}\left(e_{2}^{*}, \tau_{2}\right)>w$ where $e_{2}^{*}$ is described by equation 1. Simple algebra (see Section 9.1 in Appendix A) shows that refinancing requires

$$
x \leq \frac{w^{2}[\beta \delta-1]^{2}}{\tau_{2}}
$$

a restriction on the parameter $x$ that we assume to be satisfied (remember: the lower $x$, the higher the student's ability). This solves the problem in the second period. 
We now proceed to characterize optimal effort in the first period. We indicate with $U_{1}\left(e_{1}, \tau_{1}\right)$ the life time utility for an individual that has just enrolled

$$
U_{1}\left(e_{1}, \tau_{1}\right)=e_{1} \beta w+\left(1-e_{1}\right) \operatorname{Max}\left\{U_{2}\left(e_{2}^{*}, \tau_{2}\right) ; w\right\}-\left(\tau_{1}+\frac{x e_{2}^{2}}{2}+\lambda\right)
$$

where the max operator can be eliminated by virtue of equation 2 . As shown in Section 9.2 of Appendix A, the optimal first period effort is

$$
e_{1}^{*}=\frac{\left[\beta w-U_{2}\left(e_{2}^{*}, \tau_{2}\right)\right]}{x}
$$

Clearly the effort chosen must be a positive number. Our key empirical implication immediately follows

Proposition 1 A higher second period tuition increases effort and the graduation probability in the first period

Since $\frac{\partial U_{2}}{\partial \tau_{2}}<0$ individuals tend to work harder in the first period to avoid the larger tuition. This in turn implies that, for given quality $x$, an increase in second period tuition increases the probability of graduation. The time profile of tuition does affect the graduation probability. Tuition is a sunk cost within each period, but a forward looking student will take into account the continuation cost of education and respond accordingly.

We are now in a position to summarize the effect of a relative increase in tuition in the second period An increase in the continuation tuition $\tau_{2}$ leads to

i. $\frac{\partial e_{1}}{\partial \tau_{2}}>0$. An increase in effort and the graduation probability. This effect is our key empirical implication and motivates most of the empirical analysis that follows

ii. $\frac{\partial U_{2}}{\partial \tau_{2}}<0$. A reduction in the utility of refinancing.

iii. $\frac{\partial U_{1}}{\partial \tau_{2}}>0$ A decrease in utility from school participation. 
The second and third results are both standard and not particularly surprising. An increase in tuition reduces, other things equal, the value of education and the student's incentive to refinance. The first result is the most interesting, and highlights an important link between the time profile of tuition, effort choice and the speed of graduation. Specifically, it shows that a higher continuation tuition increases early effort and the graduation probability. This is the prediction that we test empirically in the remaining part of the paper.

\section{The Bocconi dataset and the institutional framework}

Bocconi is a private Italian university which offers undergraduate and graduate degrees in economics. The administrative data we shall use refer to a period (1992-1999) when Bocconi offered a 4-years college degree, the same length of similar economics degrees offered by public universities at that time. Since then Italian universities-as most universities in Continental Europehave shifted to 3-years undergraduate degrees.

Although it differs in many ways from the rest of the Italian university system, which is almost entirely public, Bocconi matches national averages as far as the Fuori Corso problem is concerned, which is the focus of this study. The last row of Table 2 shows that, like in the rest of the country, the median and the mean effective time to obtain a degree are higher than the legal duration but the difference is smaller at Bocconi. In line with the national pattern is also the fraction of graduates who obtain a degree in more than 4 years, which is reported in Table 3. Slightly lower than the national average is instead the fraction of Fuori Corso students among all students enrolled, confirming that, at Bocconi, students prolong their studies beyond the regular time as frequently as elsewhere but for a shorter period. This will be relevant for the interpretation of our results in Section 7 .

From the viewpoint of this study, however, the reason to focus on Bocconi data is not only its similarity with the rest of the Italian university system 
with respect to the Fuori Corso problem. More importantly Bocconi offers a unique quasi-experimental setting to analyze the effect of tuition on the probability of delaying degree completion. Upon enrollment in each academic year, Bocconi students are assigned to different tuition brackets on the basis of their income assessed by the university administration through the income tax declaration of the student's household and through further inquiries. A Regression Discontinuity Design (RDD) can thus be used to compare students who, in terms of family income, are immediately above or below each discontinuity threshold. These two groups of students pay different tuitions to enroll, but should otherwise be identical in terms of observable and unobservable characteristics determining the outcome of interest, which in our case is the decision to complete the program.

For all the 12,127 students enrolled in the four years undergraduate program at Bocconi during the period 1992-1999 we received anonymized administrative records containing information on: (a) the high school final grade and type; (b) family income as declared to the government for tax purposes; (c) the theoretical tuition assigned to each student on the basis of her declared family income; (d) the tuition actually paid, which may differ from the theoretical tuition for reasons to be explained below; (e) the exams passed in each year and the related grades; (f) demographic characteristics.

Table 4 reports some descriptive statistics suggesting that Fuori Corso status is correlated with indicators of lower ability and educational performance. For example, the fractions of students with top highschool grades, who graduate cum laude, who come from the public highschool system ${ }^{6}$ and from top highschool tracks ${ }^{7}$ are all higher for students in time than for students Fuori Corso. Interestingly, also the fraction of females is higher among those who graduate in time, while coming to Bocconi from outside Milan,

\footnotetext{
${ }^{6}$ With very few exceptions, private highschools in Italy are of a significantly lower quality, admitting those students who do not survive in the public school system.

${ }^{7}$ These are the highschool tracks that before 1968 granted access to university programs. In 1968 access to tertiary education was completely liberalized in Italy, so that all fields and all universities could be accessed by any student independently of the previous highschool curriculum.
} 
where the university is located, does not seem to matter. ${ }^{8}$ Declared family income is on average higher for students in time, although this obviously does not say much on the causal relationship between ability to pay and Fuori Corso status, since family income may be correlated positively or negatively with students' ability. ${ }^{9}$

In the period covered by our data, students were admitted at Bocconi after an entry exam and then assigned to one of 12 tuition brackets defined in terms of family income. The highest bracket was reserved to students who accepted without discussion the highest tuition and who were therefore exempted from producing their family's tax form. Since we have no income information on the students assigned to this bracket, we drop them from the analysis. Note that these students are in any case likely to be located far away from any relevant discontinuity threshold. The temporal evolution of tuition in the 11 remaining brackets is described in Figure 1. It should be noted that, for Italian standards, tuition at Bocconi is fairly high, ranging, for the observed 11 brackets, between 715 and 6,101 euro per year (in constant 2000 prices). In order to focus closely on the continuation decision beyond normal completion, we restrict the analysis to students in the 4th year of the program, i.e. the last regular year of studies. ${ }^{10}$ This restriction leaves us with 10,216 students, whose distribution across theoretical tuition brackets and Fuori corso status is described in Table 5.

Note that students enrolled in the 4th and last regular year of the program do not know the tuition they would have to pay if they remained enrolled beyond the normal completion time. This because they do not know with certainty the future income of their parents and the future possible readjustments of the tuition structure (both in terms of levels and discontinuity thresholds) implemented by Bocconi from year to year. As a consequence,

\footnotetext{
${ }^{8}$ Bocconi is one of the very few Italian universities that attracts students from far away.

${ }^{9}$ Given the relatively high tuition at Bocconi, for Italian standards, students with poor family backgrounds or coming from far away with higher mobility costs, typically enroll only if they have better highschool grades, which suggest higher ability.

${ }^{10}$ These students are observed between 1995 and 2002, since they first enrolled between 1992 and 1999.
} 
to choose their optimal level of effort during the 4th year, they must rely on a prediction of what their continuation tuition would be. We estimate that the coefficient of a regression of the tuition paid by a student in a given year on the tuition paid the year before, controlling for income and year effects, is 0.81 with a standard error of $0.004 .^{11}$ Thus, tuition in a given year is a good predictor of tuition in the following year, and, more specifically, tuition in the 4th year is a good proxy of what the students would pay if they went Fuori Corso. So the main proposition of the theoretical model presented in Section 4 can be tested in our experiment by replacing the continuation tuition, unknown to 4th year students, with their 4th year tuition and by looking at whether it has any causal effect on the speed of graduation.

All Bocconi students - with the only exception of those who accept the highest tuition bracket - are asked to produce the tax declaration from the previous fiscal year, which reports their family's income. This is the first of three institutional features of our setting that make the RDD design of this paper different from a standard design and that require proper consideration in our analysis. Families can in principle control their declared taxable income in order to be assigned to a lower bracket. As a result, while in a typical RDD subjects cannot control the indicator that determines exposure to treatment, in our case they can and this may cause an endogenous sorting of students around a discontinuity threshold. Although this is a possibility we find no evidence that it actually takes place, as shown in Figure 2, which plots the histogram of family incomes for 4th year students around two representative discontinuity threshold, the second and the seventh, and the associated estimate of the density function obtained by smoothing the histogram by a fourth degree polynomial separately on the left and on the right of the threshold. If sorting were important we should find a discontinuity in the density function at the threshold and specifically a concentration of probability mass immediately below it. It is evident from the figure that this does not happen at these two thresholds (as well as at the others not

\footnotetext{
${ }^{11}$ This estimate is based on all the 12,127 students enrolled at Bocconi during the period 1992-1999 for which we received the data.
} 
reported to save on space): if anything, the probability mass is concentrated above the discontinuity. We also implemented a parametric version of the test proposed by McCrary (2007) to check for the continuity of the density function at the threshold. The t-statistics of the tests associated to the ten discontinuities are all largely insignificant.

The second institutional feature that differentiates our RDD from the standard design relates to the fact that Bocconi reserves the right to make its own re-assessment of a family's ability to pay on the basis of further inquiries. As a result of this re-assessment a student may be assigned to a higher tuition level than the one implied by her declared taxable income. Moreover, for a variety of reasons (e.g. merit, orphan because of "war or assimilated reasons", child of emigrants, etc.), students may have a right to partial or total tuition exemptions, and may also end up paying less than what would be implied by their taxable income.

Figure 3 shows, again for 4th year students, what this means at the second and the seventh representative thresholds that we have already examined. In each panel the low theoretical tuition corresponding to each threshold has been normalized to 1 . Consider the panel for the seventh threshold. The dark bars are the histogram of the tuition effectively paid by students who in theory should pay the low theoretical level 1 (i.e. they have an income lower than the cut-off point). The tallest dark bar corresponding to 1 indicates that approximately $50 \%$ of the students who should pay the low tuition effectively pay it. The other dark bars indicate that the remaining half of the students assigned to the low theoretical tuition pay substantially more or less than what should theoretically happen on the basis of the fact that their income is below the cut-off point. The light bars can be interepreted in the same way for the students who should pay the high theoretical tuition corresponding to the seven threshold. Also in this case the tallest light bar indicates that most students effectively pay the high theoretical tuition to which they are assigned (because their income is above the cut-off point), but many do not comply with the assignment, i.e. they pay a tuition that differs from the theoretical one. The same happens for the second threshold in the 
other panel of the figure, as well as for the other thresholds not reported to save space. Bocconi, unfortunately, refused to give us full information on the specifc reasons of deviations from theoretical tuition for the cases in which this happens and thus we cannot control for it. Nevertheless, our analysis must take into account that while in the vicinity of a threshold assigned tuition is binary, tuition actually paid is potentially continuous and effectively multi-valued and this means that our RDD differs from the conventional "binary assignment - binary treatment" design in which counterfactual causal analysis is typically framed. ${ }^{12}$.

The third important way in which the RDD of this paper deviates from the standard design is a direct consequence of the second. It is evident from Figure 3 that our experimental framework features a large amount of non-compliance with the assignment: in other words many students pay a tuition level that differs from the one that they should pay theoretically as a function of where their income is located with respect to the discontinuity points. Moreover, Table 6 shows that this non-compliance is correlated with relevant (i.e. non-ignorable) observable characteristics. In our context, in which treatment is multivalued, this is equivalent to a fuzzy RDD, but what is potentially more problematic is that it may imply a significant violation of the monotonicity assumption which, as discussed in Section 6 below, is needed for identification in a RDD. ${ }^{13}$ This assumption requires that, at each threshold, students assigned to the lower theoretical tuition do not effectively pay more than if they had been assigned to the higher theoretical tuition of the same threshold. Consider a student with a family income immediately below a threshold. Bocconi has a stronger incentive to open her file and re-assess her income than if the student had been located immediately above the threshold, because in the first case a small re-assesment would be enough to increase the tuition obtained from this student. However, once the file is open the re-assesment may be large and imply a large increase in tuition. As a result, it is possible that the same student pays effectively more if

\footnotetext{
${ }^{12}$ See, for example, Hahn, Todd and van der Klaauw, 2001.

${ }^{13}$ See, Angrist, Imbens and Rubin (1996) and Hahn, Todd and van der Klaauw (2001).
} 
assigned immediately below a threshold than if assigned immediately above, and this would imply a violation of monotonicity. A similar reasoning holds for the case of a student assigned immediately above a threshold. In this cases she will have a stronger incentive to ask for a tuition exemption than if she had been assigned by family income to a threshold immediately below. In Section 6.4 we will perform a formal test suggesting that monotonicity is effectively violated in our context, but we will also show that our data feature a specific case in which this violation does not prevent the identification and interpretation of the causal effect we are interested in.

Finally, as shown in Figure 4, many variables which are relevant for our evaluation study display a significant time variation in these years. While little can be said on the determinants of this time variation, our econometric analysis will have to control for it in an appropriate way when pooling together observations from different years.

\section{The evidence}

\subsection{A Regression Discontinuity Design for our prob- lem}

Let $y_{j}$ be the $\mathrm{j}$-th discontinuity point corresponding to the income level that separates tuition brackets $j$ and $j+1$ in the theoretical assignment rule adopted by Bocconi University. We focus on the identification of causal effects for students in a neighborhood of this discontinuity point. Let $Y$ be the student's real income and $\tau^{t}$ be the theoretical tuition that the student should pay according to the assignment rule, with $l$ and $h$ being the values of $\tau^{t}$ respectively below and above the discontinuity point $(h>l) .{ }^{14}$ Denote with $\tau_{h}^{p}\left(\tau_{l}^{p}\right)$ the tuition that a student in a neighborhood of the discontinuity would actually pay if the theoretical tuition assigned to her were $h(l)$. As explained in Section 5 , both $\tau_{h}^{p}$ and $\tau_{l}^{p}$ are potentially continuous and effectively multi-

\footnotetext{
${ }^{14}$ In principle, a subscript $j$ should be attached to the values of the theoretical tuition, but since in this sub-section we consider only one generic threshold $j$ we omit this subscript to simplify notation. It will instead be needed later in Section 6.4.
} 
valued. Finally, let $F_{h}\left(F_{l}\right)$ be the binary Fuori Corso status of a student under the theoretical tuition assignment $h(l)$.

Under the continuity conditions

$$
\begin{aligned}
& E\left\{F_{l} \mid Y=y_{j}^{+}\right\}=E\left\{F_{l} \mid Y=y_{j}^{-}\right\} \\
& E\left\{\tau_{l}^{p} \mid Y=y_{j}^{+}\right\}=E\left\{\tau_{l}^{p} \mid Y=y_{j}^{-}\right\}
\end{aligned}
$$

(see Hahn, Todd and van der Klaauw, 2001) the mean effects of being assigned to the higher theoretical tuition bracket $\tau^{t}=h$ (instead of the lower one $\tau^{t}=l$ ) on the tuition actually paid $\tau^{p}$ and on the Fuori corso status $F$ for a student in a neighborhood of the cut-off point are

$$
\begin{gathered}
E\left\{\tau^{p} \mid y_{j}^{+}\right\}-E\left\{\tau^{p} \mid y_{j}^{-}\right\} . \\
E\left\{F \mid y_{j}^{+}\right\}-E\left\{F \mid y_{j}^{-}\right\} .
\end{gathered}
$$

These are the so called Intention-to-Treat effects. For the sake of keeping the notation simple, here and below we omit time subscripts, but in our context these equations hold only conditioning on time periods. This because, as we explained at the end of Section 5, the composition of the pool of Bocconi students changed over the years with respect to some observables relevant to the outcome. It is therefore necessary to condition on the time period to make the students just above the cut-off point comparable to those just below it with respect to such observables.

To convert the Intention-to-Treat effects into a meaningful causal effect of $\tau_{p}$ on $F$ we rely on Angrist, Graddy and Imbens (2000). The exclusion restriction requires that the theoretical tuition $\tau_{t}$ affects the Fuori Corso status $F$ only through the tuition effectively paid $\tau_{p}$. This is a plausible restriction in our context. More critical is the monotonicity condition that we will discuss in Section 6.4, asserting that no one is induced to pay a lower (higher) actual tuition if exogenously moved, in terms of theoretical tuition, from $l$ to $h$ (from $h$ to $l$ ). Under these assumptions, the ratio

$$
\Lambda\left(y_{j}\right)=\frac{E\left\{F \mid y_{j}^{+}\right\}-E\left\{F \mid y_{j}^{-}\right\}}{E\left\{\tau^{p} \mid y_{j}^{+}\right\}-E\left\{\tau^{p} \mid y_{j}^{-}\right\}},
$$


identifies the mean effect of a unit change in $\tau^{p}$ on the probability of going Fuori Corso at $Y=y_{j}$ for those who are induced to pay a higher actual tuition because their theoretical tuition increases from $l$ to $h$. This is a mean effect in the following sense. At the individual level the mean is taken by averaging over the causal effect of $\tau^{p}$ on $F$ specific to that student at each value of $\tau^{t}$ in the range $(l, h)$. Then, such individual-specific mean effects are averaged over the pool of students whose actual tuition increases with the theoretical one.

\subsection{Graphical evidence}

Figure 5 plots nonparametric regressions of the variables $\tau^{t}, \tau^{p}$ and $F$ on $Y$ respectively for 4 th year students at the discontinuity thresholds 2 and 7 , which are representative of what we obtain in the other cases. The regressions are estimated separately above and below the cut-off points to let the possible jump at the threshold show up if it exists. Thus, these plots offer a visual image of the intention-to-treat effects defined in equations (6) and (7).

The tuition $\tau^{p}$ effectively paid by the student is uniformly not lower than the theoretical tuition $\tau^{t}$ on both sides of the threshold. However, while at the cut-off point 7 the mean value of $\tau^{p}$ above the threshold is higher than the mean value below, the reverse happens at the cut-off point 2 . This again suggests the possibility that the monotonicity condition is violated.

As for the main outcome of interest, the probability to observe $F=1$ is higher above the cut-off point for discontinuity 7 , but the opposite happens at the second discontinuity. However, the mean impact of $\tau^{p}$ on $F$, which is the ratio between the jump of $\operatorname{Pr}(F=1)$ and the jump of $\tau^{p}$, turns out to be negative at both discontinuities. This implies that in both cases the probability of going Fuori Corso changes in the opposite direction with respect to the tuition effectively paid when the threshold is crossed.

To gather evidence on the validity of the continuity conditions (4) and (5) on which our identification strategy relies, we implement an over-identification test following Lee (2006). Consider the set of pre-intervention outcomes that 
meet the following two conditions: they should not be affected by the tuition system of fourth-year students at Bocconi University, but they should depend on the same unobservables (e.g. ability), likely to affect the Fuori Corso status $F$. Two pre-intervention outcomes satisfying these requirements are family income before enrollment at Bocconi and the grade that a student receives in her final exam at the end of highschool. Both these variables are observed at least three years before the fourth year at Bocconi in which our quasi-experiment is framed. If we found that students on the two sides of a discontinuity point differ with respect to these variables, we would have to conclude that our identification strategy fails since students assigned to $\tau^{t}=h$ are presumably not comparable to student assigned to $\tau^{t}=l$ with respect to unobservables relevant for the outcome $F$. Figure 6 shows that no discontinuity of this kind emerges at the representative discontinuities 2 and 7. A formal test confirming this evidence is described below in Section 6.3.

More generally, in the next Section we go beyond the visual evidence presented so far, showing how the estimates obtained separately at each threshold can be aggregated in a single overall estimate. In Section 6.4 we will then assess the robustness of these estimates with respect to violations of monotonicity.

\subsection{Aggregation of the mean effects at different thresh- olds}

By aiming at a single aggregate estimate of the causal effect of the tuition effectively paid on the probability of going Fuori Corso we gain precision at the expense of some insight into how the mean effect of interest varies with $Y$. Following Angrist and Lavy (1999), an overall estimate can be obtained from the equation

$$
F=g(Y)+\beta \tau^{p}+\gamma_{t}+\epsilon
$$

where $g(Y)$ is a fourth order polynomial in $Y$ and $\tau^{t} \perp \epsilon$ is used as an instrument for $\tau^{p}$. For the reasons explained at the end of Section 5, we include year-specific effects $\gamma_{t}$ in this regression. This IV estimate of the mean ef- 
fect is a weighted average of the RDD estimates at each discontinuity point, where the weights are proportional to the local covariances $\operatorname{cov}\left(\tau^{p}, \tau^{t} \mid Y=y_{j}\right)$, $j=1,10$.

In Table 7 we report the Intention-to-Treat, the OLS and the IV results for the analysis of the Fuori Corso outcome based on equation (9) estimated separately at each discontinuity point. The final row contains aggregate results based on the entire sample. There is not enough precision to trust the estimates obtained separately for each discontinuity point, but when we focus on the overall estimates in the last row, the results are sufficiently precise.

The overall Intention-to-Treat effect of $\tau^{t}$ on $\tau^{p}$ (column 1) indicates that each additional euro of theoretical tuition converts into .59 euro of tuition actually paid. This because, in the data, the downward readjustment for students on the right of a threshold is on average more frequent and/or larger than the upward readjustment for students on the left. However, despite this dilution, the overall Intention-to-Treat effect of $\tau^{t}$ on $F$ (column 2 ) suggests that a tuition increase of 1,000 euro in the 4th year would decrease by 3.6 percentage points the probability of going Fuori Corso, with respect to a sample average of approximately $80 \%$. As we explained at the end of Section 5, since 4th year students use their current tuition to predict their future tuition, we interpret this result as an estimate of the causal effect of continuation tuition on the speed of graduation.

While the OLS regression of $F$ on $\tau^{p}$ suggests a positive effect of the tuition effectively paid on the probability of going Fuori Corso (column 3), the IV estimate of the same effect is -.061 and is statistically significant (column 4). This means that a 1,000 euro increase in the 4th year paid tuition reduces the probability of late graduation by 6.1 percentage points, an effect that should again be evaluated with respect to a sample average of $80 \%$ Fuori Corso students. The large bias of the OLS estimate is due to the confounding factors (e.g. ability) which are instead controlled for by our Regression Discontinuity Design. Note that since the predicted value of continuation tuition is 0.81 the value of 4 th year tuition (see the last 
paragraph of Section 5), the estimated effect of 6.1 percentage points should be divided by 0.81 to obtain the causal effect of continuation tuition on the probability of late graduation. In other words, the effect of 4 th year tuition is likely to underestimate the effect of continuation tuition.

These results rest of course on the validity of the continuity conditions (4) and (5) for which we now provide formal support following Lee (2006). The test is implemented by running the same IV regression (9) using as a dependent variable a battery of pre-intervention outcomes. The evidence is reported in Table 8. The first pre-intervention outcome that we consider is family income before enrollment at Bocconi. This outcome allows to test not only the validity of the continuity conditions but also the conclusion, based on Figure 2, that even if families controlled their taxable income there would be no sorting around thresholds (see Section 5). A negative estimate of the IV coefficient on $\tau^{p}$ in this equation (and of the corresponding ITT) using $\tau_{t}$ as an instrument, would indicate that students below the cut-off points in their 4th year have a disproportionally higher (real) family income three years before. This would suggest the possibility that some of these students are in fact richer but have manipulated their income just enough to pay less once they enroll at Bocconi. No such evidence emerges in the first row of Table 8. The intention to treat estimate in the first column indicates that a 1,000 euro increase in the theoretical tuition $\tau^{t}$ is associated with an increase of 380 euro in yearly family income before enrollment. This estimate is small, statistically not different from zero and its sign is opposite to the one expected under the sorting hypothesis. Similarly insignificant is the IV estimate in the third column. We can, therefore, exclude the existence of sorting around the thresholds on the basis of family income.

The rest of the Table presents evidence on other pre-intervention outcomes that should not be affected by the tuition system of fourth-year students while depending on the same unobservables (e.g. ability), likely to affect the Fuori Corso status F. In addition to the final highschool grade, that we already examined in Figure 6 for discontinuities 2 and 7, here we consider also three other pre-intervention outcomes: the type of highschool attended 
by the student, her regional origin and her Grade Point Average (GPA) in the first year at Bocconi. Attending a highschool designed to prepare for a university curriculum (Liceo), as opposed to one designed to prepare for direct entrance in the labor market (Istituto Tecnico e professionale), is likely to be an outcome that depends on ability without being affected by tuition at Bocconi. ${ }^{15}$ Going to Bocconi from outside Milan has significantly higher relocation costs and is typically correlated with a higher student's quality in terms of highschool and university performance. Similarly correlated with ability is the students' GPA in the first year, but note that this variable is arguably less likely to be unaffected by the time profile of tuition at Bocconi.

As in the first row of Table 8, also in the other rows of the same table each coefficient comes from a separate regression. For example, the left cell of the row corresponding to the final highschool grade indicates that a 1,000 euro increase of the theoretical tuition $\tau^{t}$ is associated with an increase of 0.19 percentage points of the grade and this estimate is not only small but also statistically not different from zero. This is exactly what we should find if our identification strategy is correct and such conclusion is confirmed in the rest of the table: these proxies of individual ability do not differ across students assigned to different levels of the theoretical tuition $\tau^{t}$ (see the first column). Moreover, no systematic difference emerges with respect to the levels of tuition effectively paid $\tau^{p}$ in the IV estimates of the third column, although $\tau^{p}$ and pre-intervention outcomes appear to be correlated in the OLS regressions reported in the second column. The last row of the table presents results in which the gender of the student is used as the dependent variable in the regression (9). Although finding the same proportion of females on both sides of the discontinuities would not support our identification assumption because gender is not obviously correlated with ability, it is still the case that finding the opposite would cast doubts on such assumption. It is therefore reassuring to find no evidence of a threat for our identification

\footnotetext{
${ }^{15}$ Although the Italian highschool system is organized according to tracks that should determine the access to college education, since 1968 all highschool graduates can access any university in any field, independently of the track chosen during secondary education.
} 
strategy from this test.

Summing up, Table 8 supports the validity of the continuity conditions (4) and (5) on which our identification strategy is based. However, before concluding that we have identified a negative and significant causal effect of tuition on the probability of late graduation, we need to address the possibility of violations of monotonicity suggested by the institutional framework and by the visual evidence presented so far. This is done in the next section.

\subsection{Testing for monotonicity and assessing the conse- quences of its failure}

While the assumption of monotonicity is reasonable in many applications, it cannot be safely made in our context since we have both theoretical reasons for the occurrence of defiance $e^{16}$ and empirical evidence that it does occur at least at some discontinuity points.

In our context, defiers are students who would pay a higher actual tuition if their theoretical tuition were to decrease from $\tau^{t}=h$ to $\tau^{t}=l$ and viceversa. As discussed in Section 5 this may happen if a theoretical assignment to a lower bracket (based on declared family income) induces the administration of Bocconi to search more actively for proofs of a student's effective higher ability to pay, or if a theoretical assignment to a higher bracket induces the student to search more actively for ways to obtain a tuition discount.

As already noted in Section 6.2, an indication that the problem might exist in our case is offered by the fact that at the second discontinuity threshold the mean actual tuition paid by students assigned to the lower bracket $\tau^{t}=l$ exceeds the mean actual tuition paid by students assigned to the higher bracket $\tau^{t}=h$ (see Figure 5). Similar evidence can be found at some other thresholds.

A formal test for the occurrence of defiance has been proposed by Angrist and Imbens (1995). The monotonicity condition in our case asserts that $\tau_{h}^{p} \geq \tau_{l}^{p}$ with the strict inequality holding at least for some subjects. In

\footnotetext{
${ }^{16}$ See Angrist, Imbens an Rubin (2006).
} 
words, no one would be induced to pay a lower actual tuition if her theoretical tuition shifted from low to high, while at least one subject should be induced to pay a higher tuition in this event. This condition is not directly testable since the two potential outcomes $\tau_{h}^{p}$ and $\tau_{l}^{p}$ of a specific student are not simultaneously observable. However, a testable implication of the inequality is that at each discontinuity the tuition effectively paid by those in a right neighborhood of the cut-off point must be stochastically larger than the tuition effectively paid by those in a left neighborhood of the same cut-off point. That is, the cumulative distribution function (cdf) for those on the right of the cut-off point should not be above the cdf for those on the left of it at any value of its support. In our case this implication is violated at some cut-off points. In Figure 7 we present the estimated difference between the cdf on the left and the corresponding cdf on the right at the second and the seventh discontinuities (.95 confidence intervals are plotted). It is evident that the stochastic dominance hypohesis is rejected at these thresholds suggesting that defiance occurs at least here. ${ }^{17}$

In general, the failure of monotonicity prevents a causal interpretation of the IV estimand. This happens because, under the continuity restrictions (4) and (5), the IV estimand (8) is equal to:

$$
\Lambda\left(y_{j}\right)=\frac{E\left\{F_{h}-F_{l} \mid y_{j}, C\right\}}{E\left\{\tau_{h}^{p}-\tau_{l}^{p} \mid y_{j}, C\right\}} \alpha\left(y_{j}\right)+\frac{E\left\{F_{h}-F_{l} \mid y_{j}, D\right\}}{E\left\{\tau_{h}^{p}-\tau_{l}^{p} \mid y_{j}, D\right\}}\left(1-\alpha\left(y_{j}\right)\right),
$$

where

$$
\alpha\left(y_{j}\right)=\frac{E\left\{\tau_{h}^{p}-\tau_{l}^{p} \mid y_{j}, C\right\} \operatorname{Pr}\left(C \mid y_{j}\right)}{E\left\{\tau_{h}^{p}-\tau_{l}^{p} \mid y_{j}, C\right\} \operatorname{Pr}\left(C \mid y_{j}\right)+E\left\{\tau_{h}^{p}-\tau_{l}^{p} \mid y_{j}, D\right\} \operatorname{Pr}\left(D \mid y_{j}\right)},
$$

with $D$ and $C$ being the pools of defiers and compliers, respectively. In words, $\Lambda\left(y_{j}\right)$ is a weighted average of the mean effects of $\tau^{p}$ on $F$ for compliers and defiers, respectively. In this expression, the weights add to one but do not satisfy the non-negativity condition since $E\left\{\tau_{h}^{p}-\tau_{l}^{p} \mid y_{j}, C\right\}$ is by definition

\footnotetext{
${ }^{17}$ To control for year specific effects at each discontinuity point we estimated the difference among the two cdfs and their standard errors separately for each calendar year. Then we evaluated the weighted mean of such year-specific differences using as weights the inverse of the sampling variances.
} 
positive while $E\left\{\tau_{h}^{p}-t_{l}^{p} \mid y_{j}, D\right\}$ is by definition negative. It is therefore in general possible that even if the mean effect for compliers has the same sign as the mean effect for defiers, the IV estimand $\Lambda\left(y_{j}\right)$ has the opposite sign. In this case IV would estimate a totally uninteresting and uninformative parameter.

To deal with this problem, in Appendix B we propose a simple model of the occurrence of defiance in our context and show that it has a crucial implication for our analysis: the weight $\alpha\left(y_{j}\right)$ in equation (11) should change with $j$.

On the other hand, our empirical evidence suggests that $\Lambda\left(y_{j}\right)$ in (8) does not change with $j$ in the data. This is shown in Table 9 that reports estimates based on equation (9) for the entire sample, in which the coefficient $\beta$ is allowed to differ between three groups of discontinuity thresholds. The first row of the table reports the estimate for the first three discontinuities. The other two rows report the difference with respect to the first row, corresponding, respectively, to the discontinuities 4-7 and 8-10. Inasmuch as $\beta$ estimates $\Lambda\left(y_{j}\right)$ consistently, we observe no statistically significant difference in this parameter across these three groups of thresholds. ${ }^{18}$

By inspection of equation (10), for this empirical finding to be consistent with the existence of defiers, suggested by theory and by the institutional framework, it must be the case that the mean effect for compliers is equal to the mean effect for defiers and both of them do not depend on $j$.

We can therefore conclude that the IV estimates of Table 7 can be interpreted causally as estimates of Local Average Treatment Effects (LATE). ${ }^{19} \mathrm{~A}$ 1,000 euro increase in the theoretical tuition in the last year of the program reduces the probability of late graduation by 3.6 percentage points, while an increase of the tuition actually paid reduces the same probability by 6.1 percentage point, in a context in which late graduation occurs for approximately $80 \%$ of students.

\footnotetext{
18 As already mentioned, the data do not contain enough information to disaggregate the estimates for a larger number of threshold groups.

${ }^{19}$ See Imbens and Angrist (1994).
} 


\subsection{Collateral effects}

It could be argued that in order to interpret these findings and draw policy conclusions one should know whether a higher tuition makes it more likely that students drop out ${ }^{20}$ and whether those students who try to graduate in time do so at the expense of the quality of the learning process. Table 10 rejects both these hypothesis.

The first row in this table presents estimates based on an equation like (9) in which the dependent variable is a dummy taking value 1 if the student drops out after the 4 th year. The IV estimate in the last column suggests that an increase of 1,000 euro in the tuition actually paid reduces the probability of dropping out by 0.01 percentage points. This effect is however statistically insignificant: there is no evidence that students assigned to a higher tuition or effectively paying a higher tuition are more likely to drop out. ${ }^{21}$

In the second row of the table the dependent variable is the final graduation mark received by the 4th year students in our sample who had already graduated by the time we obtained the data from Bocconi. ${ }^{22}$. This final graduation mark is a number between 66 (passing level) and 110 plus honors (Laude). ${ }^{23}$ It ranges effectively between 77 and honors with a standard deviation of 7 points, and it is determined by a committee of faculty members on the basis of the grades obtained in all the exams of the four years and in the final dissertation. The IV estimate in the last column suggests that an increase of 1,000 euro in the tuition actually paid reduces the final mark only by 0.46 points and this effect is again statistically insignificant. We conclude

\footnotetext{
${ }^{20}$ Note that in the theoretical model of Section 4 this event was ruled out to simplify the analysis in order to derive Proposition 1.

${ }^{21}$ This result differs from the evidence of Dynarsky (2005) who exploits the introduction of two large merit scholarship programs in Georgia and Arkansas to show that a reduction of college costs increases significantly the probability of completing a degree. The difference between our and her findings, concerning the effect of college costs on dropout rates, may be explained by the fact that the two studies are based on different quasi-experimental situations and identification assumptions. In particular, her study focuses on tuition differences based on merit (a minimum GPA in highschool and in college), while in our case tuition differences are independent of merit.

221010 students had not graduated yet by 2004 .

23 We consider honors as an additional point.
} 
from this result that if a higher tuition induces students to speed up their coursework in order to finish earlier, this does not happen at the expense of the quality of the learning process inasmuch as this is measured by the final grade.

\section{Discussion and extensions}

The empirical analysis has established that an increase in continuation tuition decreases the probability of late graduation without inducing more dropouts and without reducing the quality of students' performance, at least as measured by the final graduation mark. In other words, students who expect to pay more in case of delayed graduation just because they are exogenously assigned to a higher theoretical tuition, seem to exert more effort in order to graduate sooner but do not seem to learn less as a consequence of this acceleration of the learning process.

The size of the effect we have estimated - a mere 1,000 euro increase in tuition actually paid reduces the probability of late graduation by 6.1 percentage points, in a context in which late graduation occurs for approximately $80 \%$ of students - may look at first puzzling. By postponing graduation a student delays the moment she joins the labor market. This has an immediate direct cost in terms of foregone earnings during the additional time spent in school and also an indirect long term (signalling) cost in terms of wages and time to find the first job after graduation. ${ }^{24}$ We have no estimate of the indirect cost for Bocconi students, but the direct cost is likely to be large. One year after graduation Bocconi students earn on average 25,000 euro (at 2001 prices) and most of them find a job in few months. ${ }^{25}$ Not surprisingly,

\footnotetext{
${ }^{24}$ Using as instruments "quarter of birth" and "distance from nearest college at entry in junior highschool", Brodaty et al. (2006) estimate for France that a year of delay with respect to average completion time causes a significant $3 \%$ decrease of the wage and a significant $15 \%$ decrease of the probability of employment in the first five years after graduation.

${ }^{25}$ Ichino and Filippin (2005) compare data on a sample of Bocconi graduates with similar data on graduates from the State University of Milan studied by Checchi (2002). Their most conservative estimate suggests that in 2001 Bocconi graduates who had first enrolled
} 
as reported in Table 2, the effective time to degree at Bocconi, albeit longer than the legal time to degree, is significantly shorter than in the rest of the Italian university system. In comparison with these figures, 1,000 euro of additional tuition may look like a very small cost. What we have estimated, however is a marginal effect. The expected foregone income from delaying graduation by one year determines the speed at which students graduate given the existing tuition profile. What we find is that 1,000 euro make a significant difference at the margin, once the effect of the expected foregone income is already taken into account.

One thousand euro could still look too small an amount to produce such a large shift in the incentive to graduate in time. A possible additional justification is that the "value" of a given sum of money depends on how the students earns it. One thousand euro earned on a job could indeed be a relatively small sum - compared with the effect it has on the incentive to speed up graduation - but for most students the money to finance education comes effectively from their parents. An interpretation of our results is then that the psycological cost of asking one's parents, when falling behind school work, can be quite large.

Our finding - that the speed at which students decide to learn is affected by the tuition they pay - does not necessarily mean that it is socially optimal to adopt to increase continuation tuition. We do not know much about the optimal length of the learning period for given amount of notions to be learned - this is in fact an issue rarely explored in the literature. ${ }^{26}$ Each student could choose the speed that she considers optimal for herself, and different individual characteristics (including different preferences for work and leisure) could result in quite different "optimal" learning speeds. To make

in 1997 earned at least 1.5 times more than State University graduates of the same year. And $92 \%$ of Bocconi graduates had found a job within one year while the same happened for only $46 \%$ of the gratuates at the other institution.

${ }^{26} \mathrm{~A}$ related issue, also rarely explored, is the choice between a system, such as in undergraduate U.K. courses, in which almost all students finish in time (because it is fairly easy to get a passing grade) and quality is signalled by grades, and the alternative, more common in continental Europe, in which passing grades are harder to get, thus resulting in delayed graduation. 
a normative argument we need to point to reasons why individual decisions might be sub-optimal. We see at least three reasons why this might happen.

The most obvious one is that students, even in some private universities, are often subsidized. If students (or their families) fail to pay the marginal technological cost of their education they will not internalize the cost to society of keeping them one more year in school and will make decisions that are socially sub-optimal. Using the tuition profile to affect their incentives can then improve society's welfare. ${ }^{27}$

Another example is suggested by the evidence of "peer effects" in education. Peer effects in school are at work whenever there is a link between the individual cost of exercising effort and the average effort elicited by the rest of the class. There is a large and growing literature on peer effects. As already mentioned in the Introduction, the experiment conducted in Kenia and discussed in Kremer et al. (2005)-where girls who scored well on academic exams were offered cash awards and an exemption from school fees-shows that financial incentives to students' performance can have positive externalities: boys, who were ineligible for the award, also experienced an improvement in exam scores, and the same happened for girls with low pre-test scores who were very unlikely to win. Evidence of peer effects is also reported by Ding and Lehrer (2005) in the context of China and by Sacerdote (2001) for the U.S. The presence of peer effects offers another reason why it may be efficient to increase continuation tutition in order to modify students' incentives. ${ }^{28}$

\footnotetext{
${ }^{27}$ The optimal time profile of tuition has been recently analysed by Gary-Bobo and Trannoy (2004) in a model in which both students and universities face imperfect information on individuals' ability.

28 The model presented in Section 4 can easily be extended to study peer effects. Assume there is a continuum of identical individuals and that the psychological cost of education depends not only on an individual choice of effort, but also on the average effort exercised by the class. Let $\lambda$, the parameter in the cost of education that each individual takes as given be $\lambda=\lambda_{0}-\lambda_{1} \bar{e}$ where $\bar{e}$ is the average effort of the class. The cost function now implies a positive externality between the effort decision of each individual and the effort of other students. Studying requires less fatigue when other people also work hard: a peer externality. Since each individual takes as given the average effort, the decentralized equilibrium is identical to the model solved in the Section 4. A central planner that maximizes average effort would however internalize the peer externality. Let $\tilde{e}_{2}$ be the choice of effort by the central planner that takes into account the peer externality. It is
} 
Externalities, however, can also be negative. By postponing graduation students can produce congestion, in the classroom, the libraries, etc. This can negatively affect the learning process of their colleagues. Although our empirical work is mute on these normative issues, they each suggest relevant arguments why using the time profile of tuition to change the speed at which a student learns could be optimal.

Finally a higher continuation tuition is likely to affect the decision to enroll in a university, an issue on which our data are silent. If such a profile were implemented keeping constant early tuition, fewer people would enter. Conversely, if the early tuition were reduced, keeping the expected total cost of enrollment constant, the effect on entry would be difficult to predict. This because it would depend on the students' assessment of their own ability and on the odds of graduation for given ability. We leave the discussion of these issues to future research.

\section{Conclusions}

This paper questions the way in which university tuition is typically structured as a function of the year of enrollment of a student. The claim is that if continuation tuition were raised, the probability of late graduation would be reduced. This result could be of interest for those universities throughout the world that are concerned by the fact that their students typically graduate beyond the normal completion time - a tendency that appears to have become more pronounced recently.

We have first shown in a simple model of human capital accumulation that there exists a negative causal effect of the size of continuation tuition on

striaghforwrd to show that $\tilde{e}_{2}^{*}=e_{2}^{*}+\frac{\lambda_{1}}{x}>e_{2}^{*}$. In other words, effort is suboptimal in the decentralized equilibrium. The presence of peer effects naturally calls for an increase in tuition in the second period: As we established in Section 4, first-period tuition can not increase effort since first-period tuition is sunk and does not enter in the determination of effort, either in the first or in the second period. Conversely, an increase in second period tuition increases effort in the first period. It is easy to show that there exists a time profile of tuition that implements the efficient outcome. Setting second period tuition to $\tau_{2}+\frac{\lambda_{1} \tilde{e}_{2}}{x}$ leads to optimal effort in the second period. 
the probability of late graduation. Next we have exploited data from Bocconi University - where students are assigned to one of 12 tuition levels on the basis of their declared family income - to implement a Regression Discontinuity Design (RDD) which allows us to compare students with similar family income immediately above or below each discontinuity threshold. We show that these two groups of students pay different tuitions, but are otherwise identical in terms of observable characteristics determining the probability of late graduation. Using this source of identification, we find that 1,000 additional Euro of tuition paid in the last regular year of the program have a negative causal effect on the probability of late graduation as large as 6.1 percentage points. Since students in the last regular year use their current tuition to predict their future tuition in case of delayed graduation, we interpret this result as an estimate of the causal effect of continuation tuition on the speed of graduation. We also show that such a tuition increase does not induce more students to drop out and its effect on the speed of completion does not occur at the expense of the quality of the learning process.

We have also discussed why it might be optimal to increase continuation tuition with the goal of changing student's incentives inducing them to speed up their studies and graduate in time. We have argued that when students are subsidized, when peer effects are important or when congestion externalities are relevant, efficiency considerations suggest that continuation tuition should be raised relative to the marginal cost of providing education. More theoretical research and different data would be needed to explore the robustness of these policy conclusions.

\section{APPENDIX A}

\subsection{Optimal Refinancing at $t=2$}

Refinancing is optimal at time $t=2$ if and only if

$$
U_{2}\left(e_{2}^{*}, x, \tau_{2}\right)>w
$$


which implies

$$
e_{2}^{*} w[\beta \delta-1]+w-\tau_{2}-\frac{x e_{2}^{* 2}}{2}-\lambda>w
$$

where $e_{2}^{*}$ is described by equation 1

Simple algebra shows that the condition reads

$$
U_{2}\left(e_{2}^{*}, x, \tau_{2}\right)=\frac{w^{2}[\beta(s) \delta-1]^{2}}{x}-\tau_{2}-\lambda+w>w
$$

which is satisfied if

$$
x \leq \frac{w^{2}[\beta(s) \delta-1]^{2}}{\tau_{2}}
$$

a condition that we assume to be satisfied

\subsection{Optimal Effort at $\mathrm{t}=1$}

Let's indicate with $U_{1}\left(e_{1}, x, \tau_{1}\right)$ the life time utility for an individual at time $t=1$ that has decided to enroll. Its expression reads

$$
U_{1}\left(e_{1}, x, \tau_{1}\right)=e_{1} \beta w+\left(1-e_{1}\right) \operatorname{Max}\left[U_{2}\left(e_{2}^{*}, x, \tau_{2}\right) ; w\right]-\left(1-\tau_{2}\right)-\frac{x e_{1}^{2}}{2}-\lambda
$$

which by virtue of equation 12 can be written as

$$
U_{1}\left(e_{1}, x, \tau_{1}\right)=e_{1} \beta w+\left(1-e_{1}\right) U_{2}\left(e_{2}^{*}, x, \tau_{2}\right)-\left(1-\tau_{2}\right)-\frac{x e_{1}^{2}}{2}-\lambda
$$

The optimal effort reads

$$
e_{1}^{*}=\frac{\left[\beta w-U_{2}\left(e_{2}^{*}, x, \tau_{2}\right)\right]}{x}
$$

\section{Appendix B}

Let $Y_{p}$ be the permanent income of the student and let it differ from $Y$ because of a transitory shock. The theoretical tuition is assigned on the basis of $Y$ according to the function $\tau^{t}(Y)$, but the administration can acquire collateral information on the student's permanent income on the basis of which it can decide to move the student's tuition to $\tau^{p}=\tau^{t}\left(Y_{p}\right)$. We assume that the administration changes the student's tuition if and only if the gain for the administration is large enough, i.e. if $\tau^{t}\left(Y_{p}\right)-\tau^{t}(Y)>c$ with $c$ a positive scalar. 
As a result, the link between the tuition actually paid by a student whose current income is in a neighbourhood of the j-th cut-off point, its current income and its theoretical tuition is:

$$
\tau^{p}=\tau^{t}\left(Y_{p}\right) \Longleftrightarrow \tau^{t}\left(Y_{p}\right)>c+l_{j}+\left(h_{j}-l_{j}\right) Z
$$

otherwise she pays $\tau^{p}=\tau^{t}(Y)$, where $Z=I\left(Y \geq y_{j}\right)$.

We can now distinguish between different relevant cases. The first one is the case in which $\tau^{t}\left(Y_{p}\right)>c+h_{j}$. This is the case in which the administration believes that the student has a high permanent income and raises her actual tuition to $\tau^{t}\left(Y_{p}\right)$ no matter for the theoretical assignment $Z$ and therefore independently of the side of the discontinuity threshold to which the students is assigned by transitory income. This is a case in which tuition actually paid by the student would be the same on the two sides of the cut-off point.

A second case is the one in which $\tau^{t}\left(Y_{p}\right)<c+l_{j}$, meaning that the administration does not modify the result of the theoretical assignment $Z$. This is a case in which perfect compliance occurs.

The third and intermediate case, in which $c+l_{j}<\tau^{t}\left(Y_{p}\right)<c+h_{j}$, is the one that can generate defiance. In this case the administration raises the tuition of the student to $\tau^{t}\left(Y_{p}\right)$ only if transitory income assigns the student to the lower tuition bracket (i.e. if $Z=0$ ). If instead transitory income assigns the student above the threshold (i.e. if $Z=1$ ), Bocconi is willing to leave the tuition unchanged. As a consequence, defiance occurs if $h_{j}<\tau^{t}\left(Y_{p}\right)<c+h_{j}$, because in this case if $Z=1$ Bocconi leaves tuition at $h_{j}$, while if $Z=0$ Bocconi raises tuition above $h_{j}$. On the contrary, compliance prevails if $c+l_{j}<\tau^{t}\left(Y_{p}\right)<h_{j}{ }^{29}$, because in this case Bocconi leaves tuition at $h_{j}$ if $Z=1$, while if $Z=0$ tuition is raised above $l_{j}$ but not above $h_{j}$.

A similar line of reasoning, applies to the behaviour of the student who has to decide whether to ask for exemption from tuition or not. Applying for an exemption is worthwhile only if the gain is sufficiently large to overcome the cost of the application, that is if $\tau^{t}(Y)-\tau^{t}\left(Y_{p}\right)>b$ with $b$ a positive constant.

\footnotetext{
${ }^{29}$ Provided that $c+l_{j}<h_{j}$. To simplify the discussion, we maintain that this condition is satisfied in what follows.
} 
An obvious implication of this model is that in general the weight $\alpha\left(y_{j}\right)$ in (11) depends on $j$. This because the distribution of $Y_{p} \mid y_{j}$ and of $\tau^{t}\left(Y_{p}\right) \mid y_{j}$ as well as the theoretical tuitions $h_{j}$ and $l_{j}$, which are relevant to define the domains of integration over which the expected values in (11) are evaluated, depend on $j$. 


\section{References}

Altonji, Joseph G. (1993), "The Demand for and Return to Education When Education Outcomes are Uncertain", Journal of Labor Economics, Vol. 11, No. 1, pp. 48-83

Angrist, Joshua D. and Guido W. Imbens (1995), "Two-Stage Least Squares Estimation of Average Causal Effects in Models with Variable Treatment Intensity", Journal of the American Statistical Association 90, 431-442.

Angrist, Joshua D., Guido W. Imbens and Donald B. Rubin (1996), "Identification of Causal Effects Using Instrumental Variables", Journal of the American Statistical Association 91, 444-472.

Angrist, Joshua D. and Victor Lavy (1999) "Using Maimonides rule to estimate the effect of class size on scholastic achievment", Quarterly Journal of Economics, May, pp. 533-575

Angrist, Joshua D. and Victor Lavy (2002), " The Effect of High School Matriculation Awards: Evidence from Randomized Trials", NBER Working Paper No. 9389

Angrist, Joshua D., Kathryn Graddy and Guido W. Imbens (2000), "The Interpretation of Instrumental Variables Estimators in Simultaneous Equations Models with an Application to the Demand for Fish", Review of Economic Studies, Vol. 67, Issue 3, pp. 499-527

Angrist, Joshua D., Daniel Lang and Philip Oreopoulos (2006), "Lead them to water and pay them to drink: an experiment with services and incentives for college achievement ", NBER Working Paper No. 12790

Brodaty, Thomas O., Robert J. Gary-Boboy and Ana Prieto, (2006) "Does Speed Signal Ability? The Impact of Grade Repetitions on Employment and Wages", Paris School of Economics, mimeo.

Booth, Alison L. and Stephen E. Satchell (1995), "The Hazards of Doing a PhD: An Analysis of Completion and Withdrawal Rates of British PhD Students in the 1980s", Journal of the Royal Statistical Society Series A, Vol. 158, No. 2, pp. 297-318

Bound, John, Michael Lovenheim and Sarah Turner (2006), "Understanding the Increased Time to the Baccalaureate Degree", mimeo, Univesrsity of Michigan 
Bowen, William G. and Neil L. Rudenstine (1992), "In pursuit of the PhD", Princeton University Press Princeton, NJ

Brunello, Giorgio and Rudolf Winter-Ebmer (2003), "Why do students expect to stay longer in college? Evidence from Europe", Economics Letters, Vol. 80, No. 2, pp. 247-253

Checchi, Daniele, (2002), "Formazione e Percorsi Lavorativi dei laureati dellUniversità degli Studi di Milano", Working Paper n. 14.2002, Università Statale of Milan.

Canadian Association for Graduate Studies (2003) "The Completion of Graduate Studies in Canadian Universities: Report and Reccomendations"

Dearden, Lorraine, Carl Emmerson, Christine Frayne, Costas Meghir, Karl Ashworth, Jay Hardman, Yvette Hartfree, Sue Maguire, Sue Middleton and Debbi Smith (2002), "Education Maintenance Allowance: The First Two Years A Quantitative Evaluation", UK Department for Education and Skills Research Report No. 352

Ding, Weili and Steven Lehrer, (2005), "Do peers affect student achievement in China's secondary schools?" mimeo, Queen's University.

Dornbusch, Rudi, Andrea Gentilini and Francesco Giavazzi (2000), Italian Labor Forse Participation: Disguised Unemployment on Campus", unpublished, Igier, Bocconi University.

Dynarski, Susan (2002). "The Behavioral and Distributional Implications of Aid for College." American Economic Review 92:2, 279-285.

Dynarski, Susan (2003). "Does Aid Matter? Measuring the Effect of Student Aid on College Attendance and Completion." American Economic Review 93:1, 279-288.

Dynarski, Susan (2005). "Building the Stock of College-Educated Labor." Working paper, Kennedy School, Harvard University.

Ehrenberg, Ronald G., and Panagiotis G. Mavros (1995), "Do Doctoral Students' Financial Support Patterns Affect Their Times-To-Degree and Completion Probabilities?", Journal of Human Resources, Vol. 30, No. 3, pp. 581-609 
Filippin, Antonio and Andrea Ichino, (2005) "Gender Wage Gap in Expectations and Realizations", Labour Economics, February, 12 (1), pp. 125145 .

Gao, Hong (2002), "Examining the Length of Time to Completion at a Community College", Paper presented at the Annual Meeting of the Southern Association for Institutional Research, Baton Rouge, LA, October 12-15

Gary-Bobo Robert, J. Trannoy, A. (2004), "Efficient Tuition Fees, Examination, Subsidies", CES-Ifo Working Paper 1189

Gneezy, Uri and Aldo Rustichini (2000), "A Fine is a Price", Journal of Legal Studies, Vol. 29, No. 1, pp. 1-18

Groen, Jeffrey, George Jakubson, Ronald G. Ehrenberg, Scott Condie and Albert Yung-Hsu Liu (2006), "Program Design and Student Outcomes in Graduate Education", NBER Working Paper No. 12064

Hahn, Jinyhong, Petra Todd and Wilbert van der Klaauw (2001), "Identification and Estimation of Treatment Effects with a Regression-Discontinuity Design", Econometrica vol.69, n. 1 (January), pp. 201-209.

Hakkinen, Iida and Roope Uusitalo (2003), "The Effect of a Student Aid Reform on Graduation: A Duration Analysis", Uppsala University, Department of Economics Working Paper No. 8

Heineck, Martin, Mathias Kifmann and Normann Lorenz (2006), "A duration analysis of the effects of tuition fees for long term students in Germany", University of Konstanz, Centre for European Economic Research Discussion Paper No. 5

Hoffer, Thomas B. and Vincent Welch (2006), "Time to Degree of U.S. Research Doctorate Recipients", National Science Foundation, Directorate for Social, Behavioral, and Economic Sciences InfoBrief No. 312

Imbens, Guido W. and Joshua D. Angrist (1994), "Identification and Estimation of Local Average Treatment Effects", Econometrica, Vol. 62, No. 2, pp. $467-75$

Kane, Thomas J. (2003), "A Quasi-Experimental Estimate of the Impact of Financial Aid on College-Going", NBER Working Paper No. 9703

Kremer, M., Miguel, E. and Thornotn, R. (2005), "Incentives to Learn", mimeo, Harvard University 
Lee, David S. (2006), "Randomized Experiments from Non-random Selection in U.S. House Elections", forthcoming in Journal of Econometrics"

Leslie, Larry L. and Paul T. Brinkman (1987), "Student Price Response in Higher Education: The Student Demand Studies", Journal of Higher Education, Vol. 58, No. 2, pp. 181-204

Leuven, Edwin, Hessel Oosterbeek and Bas van der Klaauw (2006), "The effect of financial rewards on students' achievement: Evidence from a randomized experiment", mimeo, University of Amsterdam

McCrary, Justin (2007), "Manipulation of the running variable in the regression discontinuity design: a density test", NBER Technical Working Paper No. 334

Office of Scientific and Engineering Personnel (1990), On Time to the Doctorate: A Study of the Lengthening Time to Completion for Doctorates in Science and Engineering

Sacerdote, B., (2001) "Peer Effects with Random Assignment: Results for Dartmouth Roommates", Quarterly Journal of Economics 116(2), 681704 .

Siegfried, John J. and Wendy Stock (2001), "So You Want to Earn a Ph.D. in Economics? How Long Do You Think it Will Take?", The Journal of Human Resources 36, 2, 364-378

Illinois Board of Higher Education (1999), "Persistence, Completion, and Time to Degree", mimeo.

UCDavis (2004), "Undergraduate Time to Degree Completion Rates by College and Division", Office of Resource Management and Planning, Issue Report, March.

US Department of Education (2003), "The Condition of Education 2003", Institute of Education Sciences, NCES 2003-067.

van der Klaauw, W., (2002), "Estimating the effect of financial aid offers on college enrollment: a regression-discontinuity approach", International Economic Review, vol. 43, No. 4., pp. 1249-1287.

van Ours, J. C. and G. Ridder, (2003), "Fast track or failure: a study of the graduation and dropout rates of $\mathrm{Ph} \mathrm{D}$ students in economics", Economics of Education Review, vol. 22, No. 2, pp. 157-166 
Table 1: Employment, educational enrollment and educational attainment of Italian youth older than 25

\begin{tabular}{lcccc}
\hline \hline & \multicolumn{2}{c}{$25-29$} & years old: & \multicolumn{2}{c}{$35-44$ years old: } \\
& Employed & In education & Male graduates & Female graduates \\
\hline Italy & 61.1 & 14.7 & 11.0 & 11.0 \\
Finland & 61.1 & 10.7 & 32.0 & 42.0 \\
Greece & 68.7 & 6.4 & 24.0 & 19.0 \\
Spain & 69.7 & 10.4 & 25.0 & 25.0 \\
Germany & 74.9 & 7 & 30.0 & 21.0 \\
France & 76.3 & 5.4 & 21.0 & 24.0 \\
Australia & 78.4 & 4.5 & 27.0 & 32.0 \\
Canada & 78.6 & 5.6 & 39.0 & 46.0 \\
Norway & 78.7 & 11 & 28.0 & 30.0 \\
Sweden & 80.1 & 13 & 31.0 & 35.0 \\
United Kingdom & 80.3 & 3.6 & 28.0 & 26.0 \\
Belgium & 80.6 & 3.9 & 28.0 & 31.0 \\
Austria & 80.7 & 6.6 & 19.0 & 14.0 \\
Denmark & 80.8 & 11.5 & 24.0 & 32.0 \\
United States & 81.2 & 2.9 & 37.0 & 38.0 \\
Portugal & 83.9 & 4.8 & 7.0 & 11.0 \\
Switzerland & 85.1 & 5.1 & 37.0 & 21.0 \\
Ireland & 85.4 & 8.9 & 37.0 & 36.0 \\
Netherlands & 85.9 & 2.2 & 27.0 & 22.0 \\
\hline Country Average & 77.4 & 7.3 & 26.9 & 27.2 \\
\hline \hline
\end{tabular}

Source: OECD Education at a Glance, 2002. 
Table 2: Legal and effective duration of university programs in Italy

\begin{tabular}{lccc}
\hline \hline & $\begin{array}{c}\text { Mean } \\
\text { legal duration }\end{array}$ & $\begin{array}{c}\text { Median } \\
\text { effective duration }\end{array}$ & $\begin{array}{c}\text { Mean } \\
\text { effective duration }\end{array}$ \\
\hline Sciences & 4.01 & 6.0 & 6.94 \\
Chemistry and Pharmacy & 4.66 & 6.0 & 6.95 \\
Geo-biology & 4.17 & 7.0 & 7.63 \\
Medical school & 5.77 & 7.0 & 8.28 \\
Engineering & 4.99 & 7.0 & 7.73 \\
Architecture & 4.99 & 8.0 & 8.79 \\
Agrarian sciences & 4.83 & 7.0 & 8.21 \\
Economics and statistics & 4.04 & 6.0 & 6.74 \\
Political sciences & 4.02 & 6.0 & 7.23 \\
Law & 4.02 & 6.0 & 7.04 \\
Arts & 4.02 & 7.0 & 7.61 \\
Literature & 4.02 & 7.0 & 7.38 \\
Teaching & 4.01 & 7.0 & 8.55 \\
Psychology & 4.92 & 6.0 & 6.71 \\
\hline Total & 4.39 & 7.0 & 7.41 \\
\hline Bocconi University & 4.00 & 5.5 & 5.00 \\
\hline \hline
\end{tabular}

Source: Representative sample of graduates in 1995 surveyed in 1998 - Standard sample file "Indagine sull'inserimento professionale dei laureati dell'anno 1995" , ISTAT, 1998. Our sample for statistics concerning Bocconi. 
Table 3: Fraction of Fuori Corso students in Italy

\begin{tabular}{lccc}
\hline \hline & All Italy & Economics in Italy & Bocconi University \\
& & & \\
\hline & & & \\
Enrolled in year 99-00 & 1684993 & 237893 & 298 \\
\% of Fuori corso & 41.1 & 43.6 & 28.9 \\
\hline & & & 1182 \\
Graduates in year 99-00 & 171806 & 28106 & 81.2 \\
\% of Fuori corso & 83.5 & 89.9 & \\
\hline \hline
\end{tabular}

Source: Italian Ministry of Education and our sample for statistics concerning Bocconi. 
Table 4: Descriptive statistics by fuori corso status

\begin{tabular}{lccc}
\hline \hline & \multicolumn{2}{c}{ Conditional on being } & Of the total \\
& in time & fuori corso & \\
\hline \% of the 12127 enrolled from 1992 to 1999 who: & & & \\
are females & 44.62 & 39.57 & 40.92 \\
are from the Milan area & 40.58 & 40.84 & 40.77 \\
graduated from highschool with top grades & 28.83 & 22.01 & 23.83 \\
attended top highschool tracks & 70.40 & 65.98 & 67.16 \\
graduated cum laude from Bocconi & 57.76 & 23.67 & 32.79 \\
have family income (in euro) equal to & 41872 & 38637 & 39502 \\
\hline Total & 26.74 & 73.26 & 100.00 \\
\hline \hline
\end{tabular}

Source: Statistics for all the students who enrolled in the first year at Bocconi between 1992 and 1999. 
Figure 1: Time profile of tuition at Bocconi
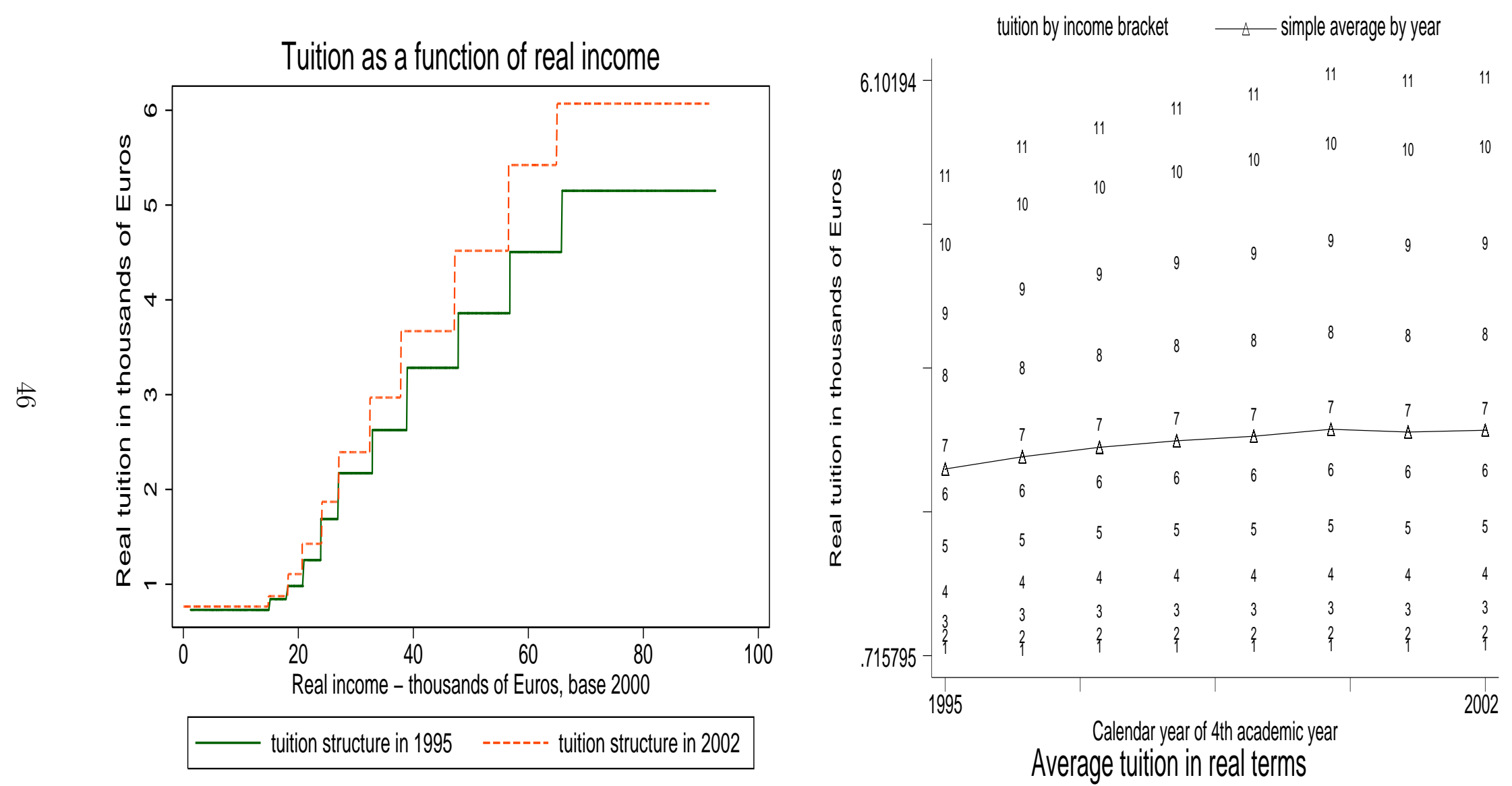

Source: Statistics for all the students who enrolled in the first year at Bocconi between 1992 and 1999. 
Table 5: 4th year students by theoretical tuition bracket and Fuori Corso status

\begin{tabular}{|c|c|c|c|c|c|c|}
\hline \multirow[t]{2}{*}{ Tuition bracket } & \multicolumn{2}{|c|}{ "in time" } & \multicolumn{2}{|c|}{ Fuori Corso } & \multicolumn{2}{|c|}{ All students } \\
\hline & n.obs. & $\%$ & n.obs. & $\%$ & n.obs & $\%$ \\
\hline 1 & 167 & 14.67 & 971 & 85.33 & 1,138 & 100.00 \\
\hline 2 & 79 & 16.09 & 412 & 83.91 & 491 & 100.00 \\
\hline 3 & 63 & 14.58 & 369 & 85.42 & 432 & 100.00 \\
\hline 4 & 117 & 17.84 & 539 & 82.16 & 656 & 100.00 \\
\hline 5 & 86 & 14.60 & 503 & 85.40 & 589 & 100.00 \\
\hline 6 & 174 & 18.20 & 782 & 81.80 & 956 & 100.00 \\
\hline 7 & 182 & 18.69 & 792 & 81.31 & 974 & 100.00 \\
\hline 8 & 356 & 21.65 & 1,288 & 78.35 & 1,644 & 100.00 \\
\hline 9 & 303 & 25.83 & 870 & 74.17 & 1,173 & 100.00 \\
\hline 10 & 194 & 24.56 & 596 & 75.44 & 790 & 100.00 \\
\hline 11 & 342 & 24.91 & 1,031 & 75.09 & 1,373 & 100.00 \\
\hline Total & 2,063 & 20.19 & 8,153 & 79.81 & 10,216 & 100.00 \\
\hline
\end{tabular}

Source: Statistics for the 4th year students who enrolled in the first year at Bocconi between 1992 and 1999. 
Figure 2: Histogram of family income around thresholds
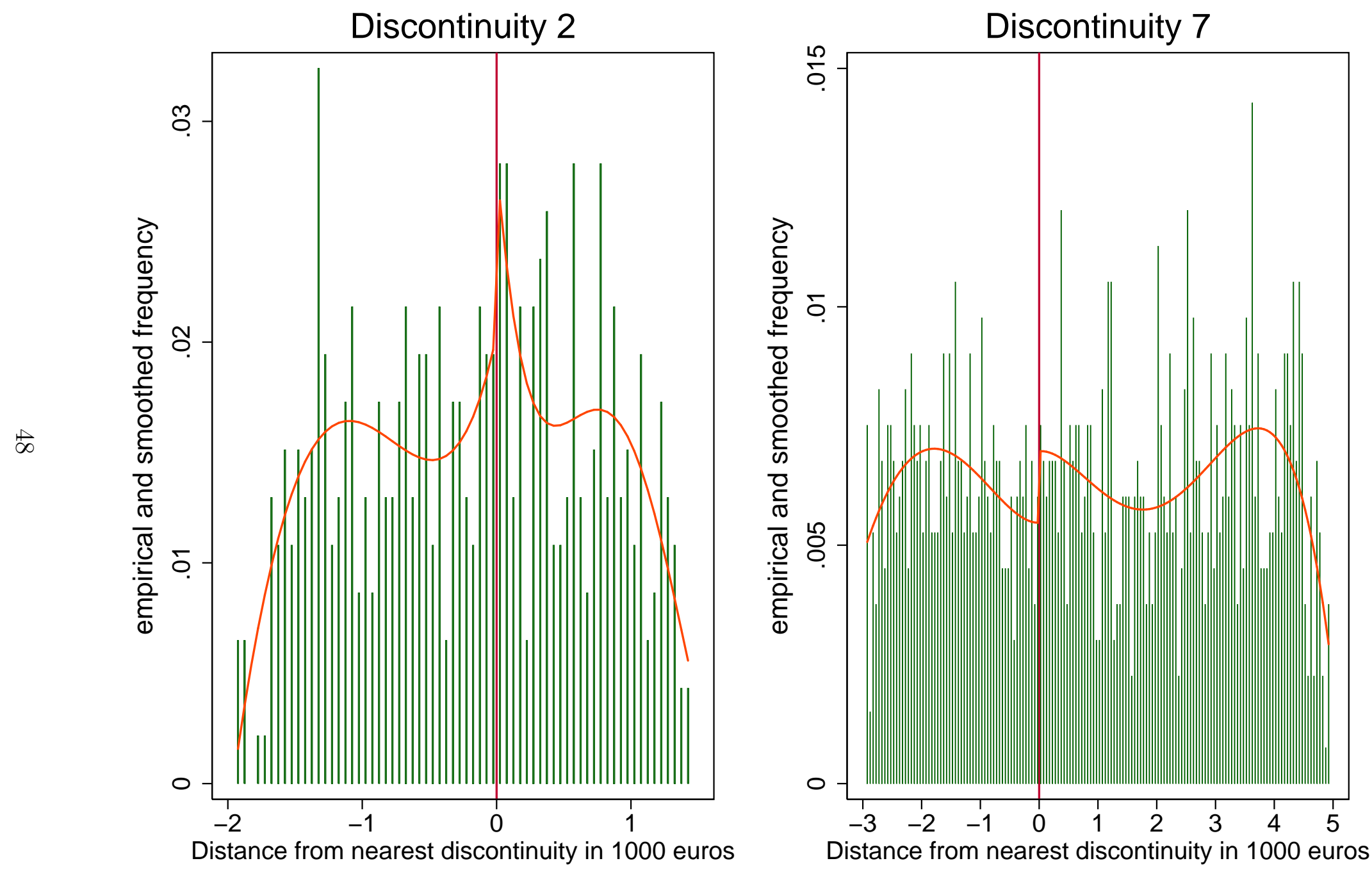

Source: Statistics for the 4th year students who enrolled in the first year at Bocconi between 1992 and 1999. 

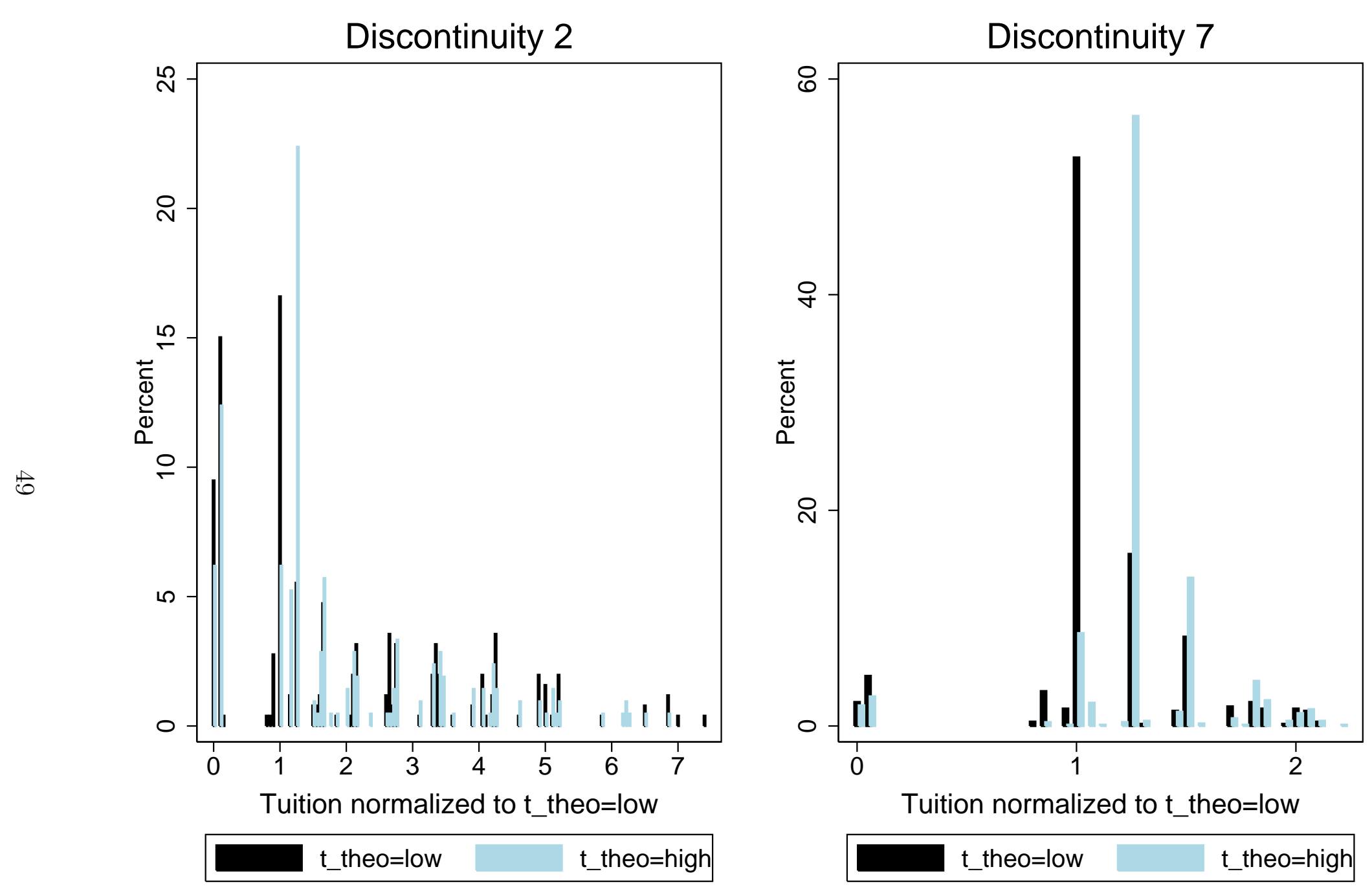

Note: For each discontinuity, all tuition levels (whether theoretical or actually paid) have been divided by $\tau^{t}=l$. Thus, for example, the histogram bar at 1 is for $\tau^{t}=l$ while the highest light bar on the right of 1 is for $\tau^{t}=h$.

Source: Statistics for the 4th year students who enrolled in the first year at Bocconi between 1992 and 1999. 
Table 6: Characteristics of 4th year students according to whether their actual tuition is equal to, larger than or smaller than the theoretical one

\begin{tabular}{|c|c|c|c|}
\hline & \multicolumn{3}{|c|}{ For given theoretical tuition, fraction paying: } \\
\hline & less & same & more \\
\hline Females & 44.02 & 40.87 & 42.22 \\
\hline From Milan area & 27.39 & 44.69 & 38.50 \\
\hline With top highschool grade & 39.34 & 25.03 & 21.76 \\
\hline From top highschool tracks & 56.99 & 71.08 & 67.06 \\
\hline
\end{tabular}

Source: Statistics for the 4th year students who enrolled in the first year at Bocconi between 1992 and 1999. The sample size is 10,216. 
Figure 4: Time trends of relevant variables
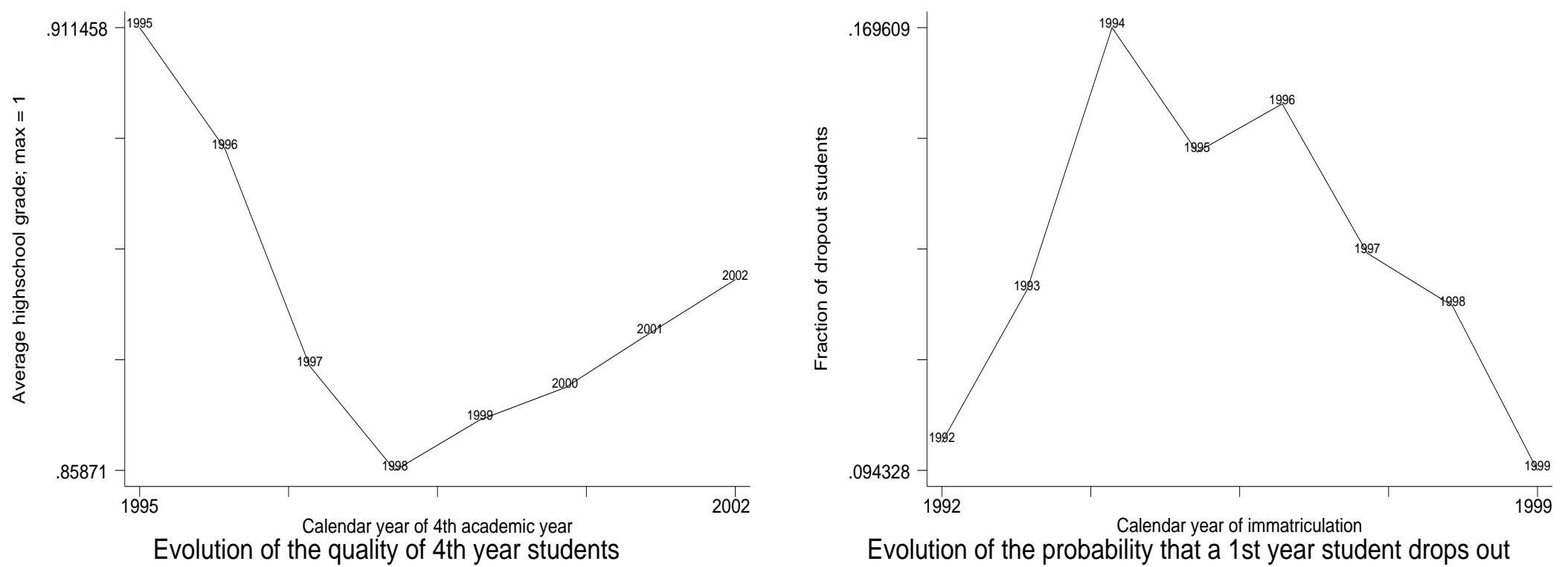

Evolution of the probability that a 1st year student drops out

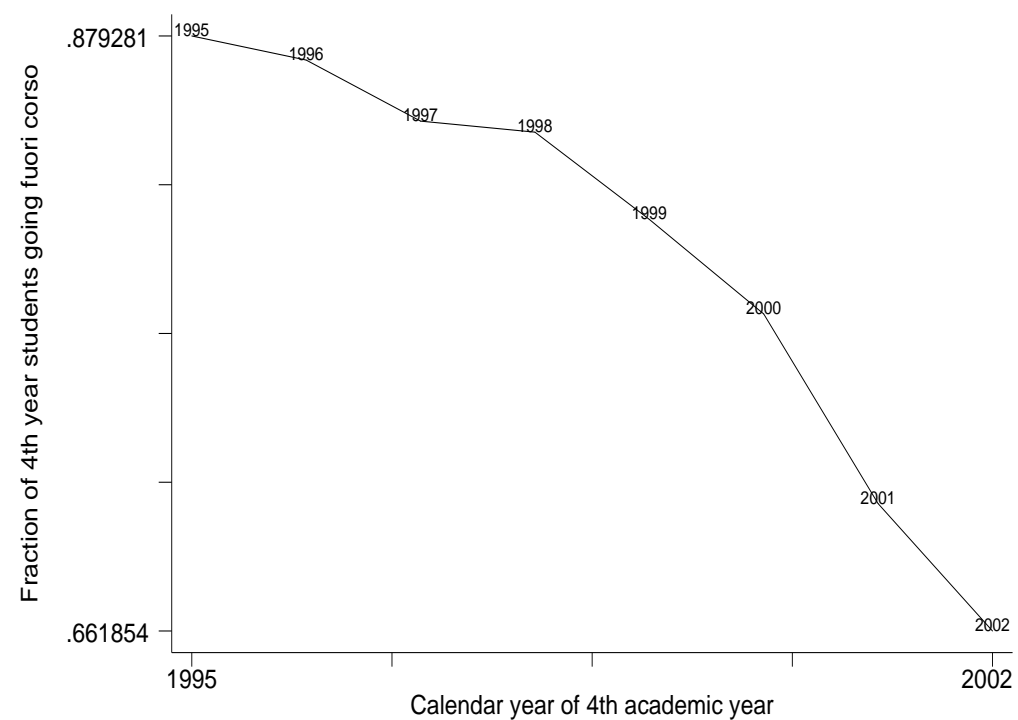

Evolution of the probability of fuori corso for 4 th year students

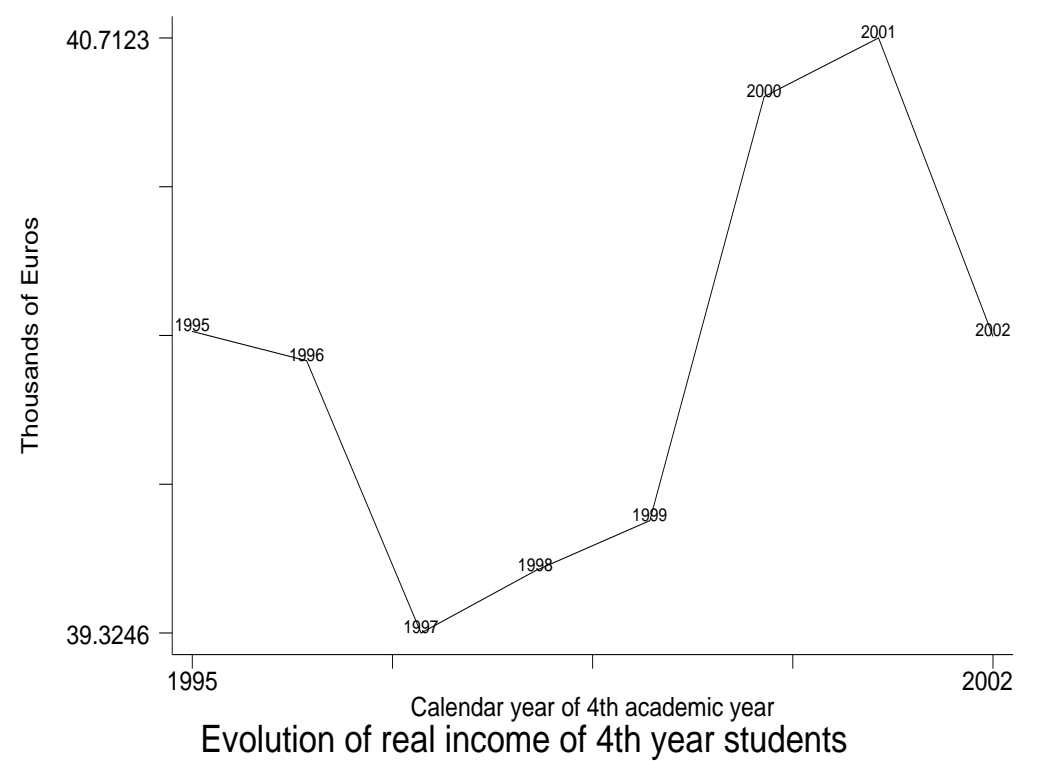

Source: Statistics for the 4th year students who enrolled in the first year at Bocconi between 1992 and 1999. 

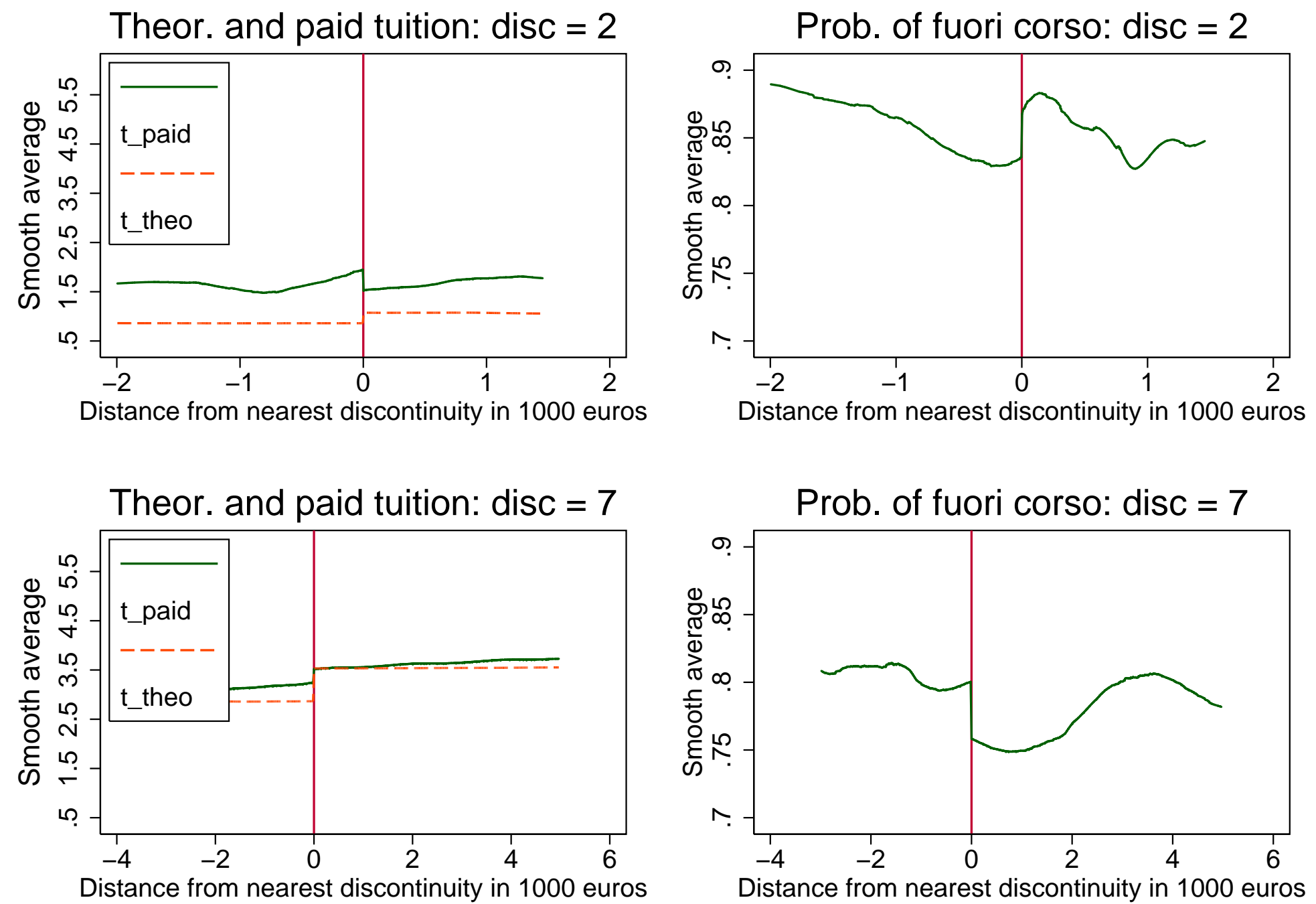

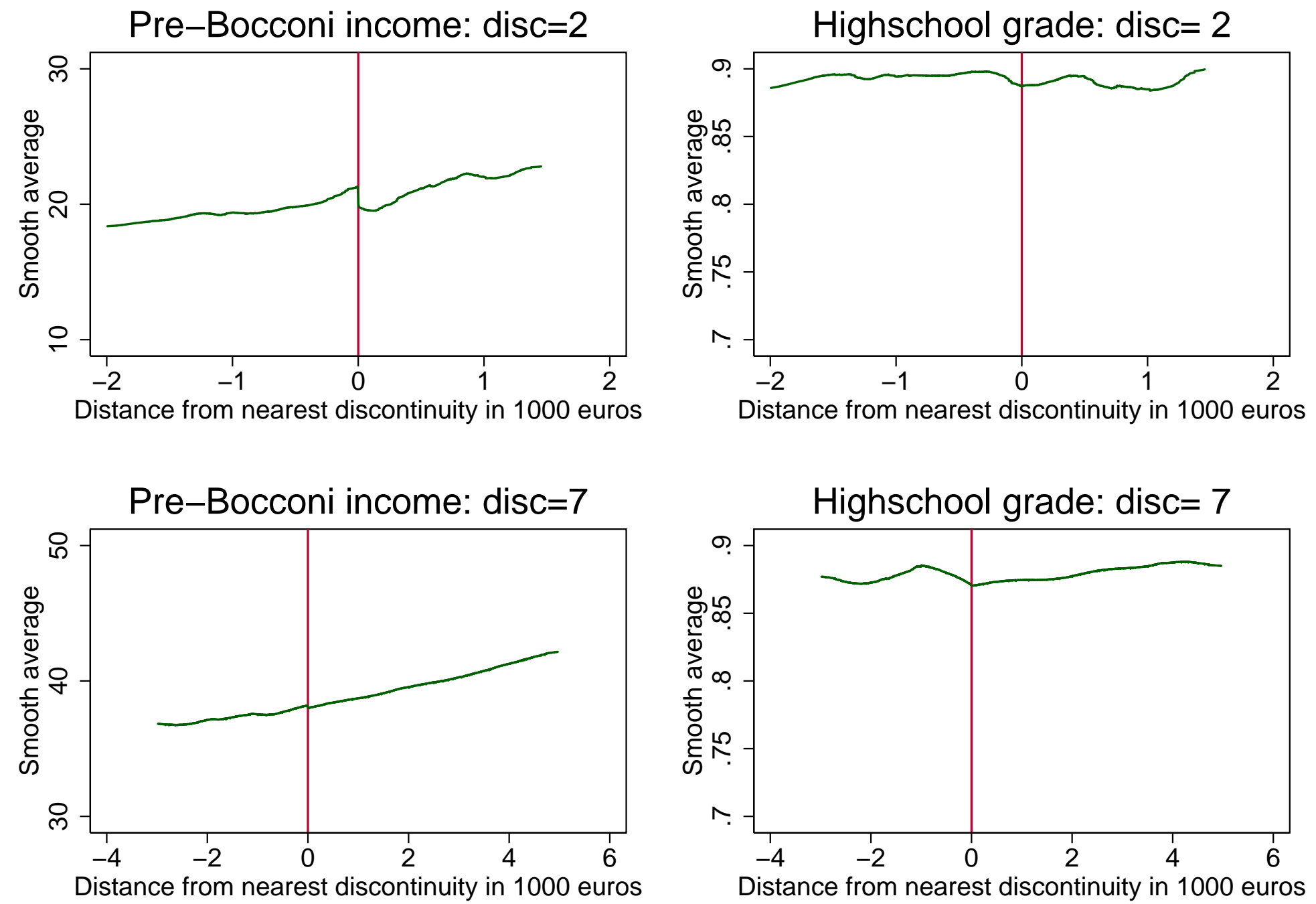
Table 7: Regression discontinuity estimates of the effect of tuition on the probability of late graduation (Fuori corso)

\begin{tabular}{|c|c|c|c|c|c|}
\hline $\begin{array}{l}\text { Method } \\
\text { Outcome } \\
\text { Treatment } \\
\text { Instrument }\end{array}$ & $\begin{array}{c}\text { OLS-ITT } \\
\text { Paid Tuition } \\
\text { Theoretical Tuition }\end{array}$ & $\begin{array}{c}\text { OLS-ITT } \\
\text { Fuori Corso } \\
\text { Theoretical Tuition }\end{array}$ & $\begin{array}{l}\text { OLS } \\
\text { Fuori Corso } \\
\text { Paid Tuition }\end{array}$ & $\begin{array}{c}\text { IV-LATE } \\
\text { Fuori Corso } \\
\text { Paid Tuition } \\
\text { Theoretical Tuition }\end{array}$ & N. of obs. \\
\hline $\begin{array}{l}\text { Discontinuity } 1 \\
\text { s.e. }\end{array}$ & $\begin{array}{l}-2.5 \\
(2.2)\end{array}$ & $\begin{array}{l}.42 \\
(.54)\end{array}$ & $\begin{array}{l}-.0086 \\
(.007)\end{array}$ & $\begin{array}{l}-17 \\
(.26)\end{array}$ & 1376 \\
\hline $\begin{array}{l}\text { Discontinuity } 2 \\
\text { s.e. }\end{array}$ & $\begin{array}{l}-2.4 \\
(1.5)\end{array}$ & $\begin{array}{l}.21 \\
(.37)\end{array}$ & $\begin{array}{l}.0047 \\
(.011)\end{array}$ & $\begin{array}{l}-.088 \\
(.16)\end{array}$ & 463 \\
\hline $\begin{array}{l}\text { Discontinuity } 3 \\
\text { s.e. }\end{array}$ & $\begin{array}{l}.64 \\
(1.2)\end{array}$ & $\begin{array}{l}-.13 \\
(.31)\end{array}$ & $\begin{array}{l}-.012 \\
(.013)\end{array}$ & $\begin{array}{l}-.2 \\
(.59)\end{array}$ & 563 \\
\hline $\begin{array}{l}\text { Discontinuity } 4 \\
\text { s.e. }\end{array}$ & $\begin{array}{l}.51 \\
(.64)\end{array}$ & $\begin{array}{l}.17 \\
(.17)\end{array}$ & $\begin{array}{c}-.0058 \\
(.01)\end{array}$ & $\begin{array}{l}.33 \\
(.54)\end{array}$ & 636 \\
\hline $\begin{array}{l}\text { Discontinuity } 5 \\
\text { s.e. }\end{array}$ & $\begin{array}{l}-.4 \\
(.54)\end{array}$ & $\begin{array}{l}-.2 \\
(.14)\end{array}$ & $\begin{array}{l}.017 \\
(.01)\end{array}$ & $\begin{array}{l}.5 \\
(.77)\end{array}$ & 742 \\
\hline $\begin{array}{l}\text { Discontinuity } 6 \\
\text { s.e. }\end{array}$ & $\begin{array}{l}.52 \\
(.41)\end{array}$ & $\begin{array}{l}-.078 \\
(.11)\end{array}$ & $\begin{array}{l}.0063 \\
(.01)\end{array}$ & $\begin{array}{l}-.15 \\
(.25)\end{array}$ & 961 \\
\hline $\begin{array}{l}\text { Discontinuity } 7 \\
\text { s.e. }\end{array}$ & $\begin{array}{l}.11 \\
(.25)\end{array}$ & $\begin{array}{l}-.06 \\
(.10)\end{array}$ & $\begin{array}{l}.011 \\
(.01)\end{array}$ & $\begin{array}{l}-.56 \\
(1.6)\end{array}$ & 1331 \\
\hline $\begin{array}{l}\text { Discontinuity } 8 \\
\text { s.e. }\end{array}$ & $\begin{array}{l}.38 \\
(.14)\end{array}$ & $\begin{array}{c}-.07 \\
(.076)\end{array}$ & $\begin{array}{l}.017 \\
(.014)\end{array}$ & $\begin{array}{l}-.19 \\
(.21)\end{array}$ & 1453 \\
\hline $\begin{array}{l}\text { Discontinuity } 9 \\
\text { s.e. }\end{array}$ & $\begin{array}{l}.24 \\
(.12)\end{array}$ & $\begin{array}{l}-.022 \\
(.09)\end{array}$ & $\begin{array}{l}.027 \\
(.02)\end{array}$ & $\begin{array}{r}-.095 \\
(.38)\end{array}$ & 957 \\
\hline $\begin{array}{l}\text { Discontinuity } 10 \\
\text { s.e. }\end{array}$ & $\begin{array}{l}.57 \\
(.12)\end{array}$ & $\begin{array}{l}.11 \\
(.09)\end{array}$ & $\begin{array}{l}.046 \\
(.022)\end{array}$ & $\begin{array}{c}.2 \\
(.17)\end{array}$ & 1734 \\
\hline $\begin{array}{l}\text { All } \\
\text { s.e. }\end{array}$ & $\begin{array}{l}.59 \\
(.05)\end{array}$ & $\begin{array}{l}-.036 \\
(.018)\end{array}$ & $\begin{array}{l}.0021 \\
(.004)\end{array}$ & $\begin{array}{l}-.061 \\
(.031)\end{array}$ & 10216 \\
\hline
\end{tabular}

Note: Each coefficient (and related robust standard error in parenthesis) is an estimate of $\beta$ obtained from separate regressions of the form:

$$
W=g(Y)+\beta \tau^{K}+\gamma_{t}+\epsilon
$$

where $W$ is the tuition actually paid $\tau^{p}$ in column 1 and the Fuori Corso status $F$ in the other columns; $\tau^{k}$ is the theoretical tuition $\tau^{t}$ in column 1 and 2 , and the tuition actually paid $\tau^{p}$ in column 3 and 4. Estimates in columns 1,2 and 3 are obtained with OLS; in column 4 with IV using $\tau^{t}$ as an instrument for $\tau^{p} . \gamma_{t}$ are time dummies.

Source: Statistics for the 4th year students who enrolled in the first year at Bocconi between 1992 and 1999. 
Table 8: Tests for the presence of sorting and for the validity of the continuity conditions

\begin{tabular}{|c|c|c|c|c|}
\hline $\begin{array}{l}\text { Method } \\
\text { Treatment } \\
\text { Instrument }\end{array}$ & $\begin{array}{c}\text { OLS-ITT } \\
\text { Theoretical Tuition }\end{array}$ & $\begin{array}{c}\text { OLS } \\
\text { Paid Tuition }\end{array}$ & $\begin{array}{c}\text { IV-LATE } \\
\text { Paid Tuition } \\
\text { Theoretical Tuition }\end{array}$ & N. of obs. \\
\hline Income before Bocconi & $\begin{array}{l}.38 \\
(.46)\end{array}$ & $\begin{array}{l}.75 \\
(.11)\end{array}$ & $\begin{array}{l}.66 \\
(.81)\end{array}$ & 9800 \\
\hline Highschool grade & $\begin{array}{c}.0019 \\
(.0048)\end{array}$ & $\begin{array}{c}-.013 \\
(.00096)\end{array}$ & $\begin{array}{l}.0032 \\
(.0082)\end{array}$ & 10216 \\
\hline Highschool type & $\begin{array}{l}-.032 \\
(.02)\end{array}$ & $\begin{array}{l}.029 \\
(.0042)\end{array}$ & $\begin{array}{l}-.055 \\
(.034)\end{array}$ & 10216 \\
\hline Family of origin outside Milan & $\begin{array}{l}-.025 \\
(.022)\end{array}$ & $\begin{array}{c}-.017 \\
(.0041)\end{array}$ & $\begin{array}{l}-.042 \\
(.038)\end{array}$ & 10216 \\
\hline GPA in first year at Bocconi & $\begin{array}{c}-.0024 \\
(.0033)\end{array}$ & $\begin{array}{c}-.0075 \\
(.00066)\end{array}$ & $\begin{array}{c}-.0041 \\
(.0057)\end{array}$ & 10153 \\
\hline Female & $\begin{array}{l}.029 \\
(.022)\end{array}$ & $\begin{array}{c}-.0068 \\
(.0044)\end{array}$ & $\begin{array}{l}.05 \\
(.038)\end{array}$ & 10216 \\
\hline
\end{tabular}

Note: Each coefficient (and related robust standard error in parenthesis) is an estimate of $\beta$ obtained from separate regressions of the form:

$$
S=g(Y)+\beta \tau^{K}+\gamma_{t}+\epsilon
$$

where $S$ is the pre-intervention outcome indicated in the corresponding row of the table; $\tau^{k}$ is the theoretical tuition $\tau^{t}$ in column 1 and the tuition actually paid $\tau^{p}$ in column 2 and 3. Estimates in columns 1 and 2 are obtained with OLS; in column 3 with IV using $\tau^{t}$ as an instrument for $\tau^{p} \cdot \gamma_{t}$ are time dummies.

Source: Statistics for the 4th year students who enrolled in the first year at Bocconi between 1992 and 1999. 
Figure 7: A test of monotonicity: CDF crossing
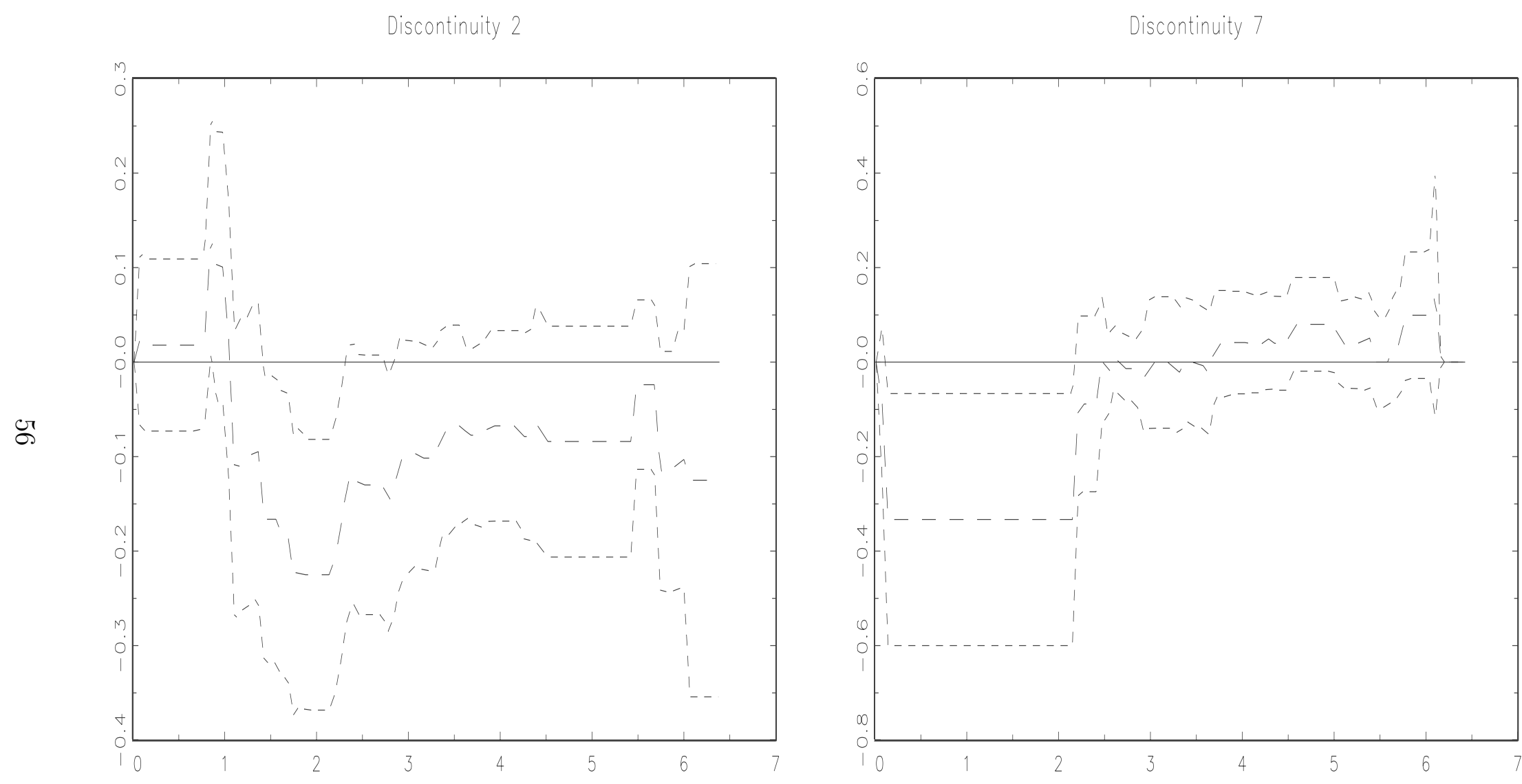

For each discontinuity the figure plots the estimated difference between the cdf of the tuition actually paid by students in a left neighbourhood of the cut-off point and the corresponding cdf paid by students in a right neighbourhood. 0.95 confidence intervals are plotted as well. The left (right) neighbourhood is defined selecting students whose family income is below (above) the cut-off point by no more than 500 euro.

Source: Statistics for the 4th year students who enrolled in the first year at Bocconi between 1992 and 1999. 
Table 9: Test for the equality of the IV estimand $\Lambda\left(y_{j}\right)$ at different discontinuity thresholds

\begin{tabular}{|c|c|c|c|}
\hline $\begin{array}{l}\text { Method } \\
\text { Outcome } \\
\text { Treatment } \\
\text { Instrument }\end{array}$ & $\begin{array}{c}\text { OLS-ITT } \\
\text { Fuori Corso } \\
\text { Theoretical Tuition }\end{array}$ & $\begin{array}{l}\text { OLS } \\
\text { Fuori Corso } \\
\text { Paid Tuition }\end{array}$ & $\begin{array}{c}\text { IV-LATE } \\
\text { Fuori Corso } \\
\text { Paid Tuition } \\
\text { Theoretical Tuition }\end{array}$ \\
\hline $\begin{array}{l}\text { IV estimand } \Lambda\left(y_{j}\right) \\
\text { at the discontinuities } \\
12 \text { and } 3\end{array}$ & $\begin{array}{l}-0.065 \\
(0.027)\end{array}$ & $\begin{array}{l}-0.008 \\
(0.005)\end{array}$ & $\begin{array}{l}-0.090 \\
(0.036)\end{array}$ \\
\hline $\begin{array}{l}\text { Deviation of the } \\
\text { IV estimand } \Lambda\left(y_{j}\right) \\
\text { at the discontinuities } \\
4,5,6 \text { and } 7\end{array}$ & $\begin{array}{c}0.019 \\
(0.016)\end{array}$ & $\begin{array}{c}0.016 \\
(0.006)\end{array}$ & $\begin{array}{c}0.015 \\
(0.013)\end{array}$ \\
\hline $\begin{array}{l}\text { Deviation of the } \\
\text { IV estimand } \Lambda\left(y_{j}\right) \\
\text { at the discontinuities } \\
8,9 \text { and } 10\end{array}$ & $\begin{array}{c}0.013 \\
(0.018)\end{array}$ & $\begin{array}{c}0.017 \\
(0.007)\end{array}$ & $\begin{array}{c}0.014 \\
(0.015)\end{array}$ \\
\hline
\end{tabular}

Note: The rows of the table report respectively the coefficients $\beta_{1,3} \beta_{4,7}$ and $\beta_{8,10}$ of the regression

$$
F=g(Y)+\beta_{1,3} \tau^{K} D_{1,3}+\beta_{4,7} \tau^{K} D_{4,7}+\beta_{8,10} \tau^{K} D_{8,10}+\gamma_{t}+\epsilon
$$

where $F$ is the Fuori Corso status; the dummies $D_{i, j}$ denote the discontinuity thresholds from $i$ to $j ; \tau^{k}$ is the theoretical tuition $\tau^{t}$ in column 1 , and the tuition actually paid $\tau^{p}$ in column 2 and 3 . Estimates in columns 1 and 2 are obtained with OLS; in column 3 with IV using $\tau^{t}$ as an instrument for $\tau^{p}$. $\gamma_{t}$ are time dummies.

Source: Statistics for the 4th year students who enrolled in the first year at Bocconi between 1992 and 1999. 
Table 10: Effect of tuition on dropout rates and final graduation marks

\begin{tabular}{lcccc}
\hline \hline $\begin{array}{l}\text { Method } \\
\text { Treatment } \\
\text { Instrument }\end{array}$ & OLS-ITT & OLS & IV-LATE & N. of obs. \\
& Theoretical Tuition & Paid Tuition & $\begin{array}{c}\text { Paid Tuition } \\
\text { Theoretical Tuition }\end{array}$ & \\
\hline Drop-out & -.006 & -.004 & -.010 & 10212 \\
& $(.008)$ & $(.002)$ & $(.013)$ & 9206 \\
\hline $\begin{array}{l}\text { Final graduation mark } \\
(\text { min=66; max }=110)\end{array}$ & -.29 & -.83 & -.46 & $(.52)$ \\
\hline \hline
\end{tabular}

Note: Each coefficient (and related robust standard error in parenthesis) is an estimate of $\beta$ obtained from separate regressions of the form:

$$
W=g(Y)+\beta \tau^{K}+\gamma_{t}+\epsilon
$$

where $W$ is a dummy for dropping out in top panel and the final graduation mark ranging between 66 and 110 (111 in case of honors) with a standard deviation of 7 points in the bottom panel; $\tau^{k}$ is the theoretical tuition $\tau^{t}$ in column 1 , and the tuition actually paid $\tau^{p}$ in column 2 and 3. Estimates in columns 1 and 2 are obtained with OLS; in column 3 with IV using $\tau^{t}$ as an instrument for $\tau^{p}$. $\gamma_{t}$ are time dummies.

Source: Statistics for the 4th year students who enrolled in the first year at Bocconi between 1992 and 1999. The smaller sample size in the bottom panel originates from the fact that 1010 studens had not graduated yet by 2004, when we received the data from Bocconi. 